\title{
LA FORMA DE GOBIERNO EN LA CONSTITUCIÓN DE CÁDIZ (REFLEXIONES SOBRE LA CONFIGURACIÓN DE LA JEFATURA DEL ESTADO MONÁRQUICA)
}

REMEDIO SÁNCHEZ FERRIZ

Y

GÖRAN ROLLNERT LIERN 


\section{SUMARIO}

1. CONSIDERACIONES PRELIMINARES. 1.1. El primer constitucionalismo español. Significación política y jurídica. 1.2. La monarquía ilustrada en España. 1.3. La herencia de la Ilustración en la obra de las Cortes de Cádiz. 2. La monarquía en el Estado constitucional que en Cádiz se establece. 2.1. La soberanía nacional. 2.2. La división de poderes. 2.3. «Monarquía moderada» y monarquía limitada. 2.4. El Rey como Jefe del Estado. 


\title{
LA FORMA DE GOBIERNO EN LA CONSTITUCIÓN DE CÁDIZ (REFLEXIONES SOBRE LA CONFIGURACIÓN DE LA JEFATURA DEL ESTADO MONÁRQUICA ${ }^{1}$ )
}

\author{
POR \\ REMEDIO SÁNCHEZ FERRIZ \\ Catedrática de Derecho Constitucional (Universidad de Valencia) \\ GÖRAN ROLLNERT LIERN \\ Profesor Titular de Derecho Constitucional (Universidad de Valencia)
}

\section{CONSIDERACIONES PRELIMINARES}

Aunque el presente estudio ha de centrarse en la institución monárquica y su consideración en el constitucionalismo gaditano, resulta necesaria una previa reflexión que nos permitirá situarnos en el contexto histórico en que el texto constitucional se elabora; pues sólo así se comprende cómo se lleva a cabo la profunda reforma institucional en Cádiz introduciendo cambios tan revolucionarios como los franceses sin, en cambio, constituir un enfrentamiento con las instituciones establecidas internamente.

1 Una primera versión de este trabajo se presentó como ponencia en el Congreso Internacional «1812: fra Cadice e Palermo —entre Cádiz y Palermo—— organizado por la Universidad de Messina en Palermo-Messina los días 5 a 12 de diciembre de 2005. 
Pero, además, resulta oportuno el recuerdo de las aportaciones doctrinales y de los logros institucionales que de carácter estructural ya se introducen en el medio siglo precedente por cuanto la apariencia de las circunstancias reales que se viven en los primeros años del siglo XIX, de extraordinario interés histórico, no es suficiente para explicar el cambio institucional y doctrinal que las Cortes de Cádiz llevan a cabo. Si acaso, contribuyen tales circunstancias más a enmascarar y dificultar el entendimiento ${ }^{2}$ de las reformas institucionales, una de las cuales constituye aquí el objeto de nuestro estudio.

La situación «fáctica» española recuerda más en la realidad a la americana que a la francesa, tanto en lo que se refiere a las circunstancias bélicas (la reacción de todas las capas sociales, incluida la popular, frente a la invasión extranjera ante la que ha de afirmarse) como al hecho de que se aprovechen esas circunstancias para reconstituir las instituciones ${ }^{3}$; es cierto que las influencias ideológicas francesas, con ser extremadas (y, por ello, temidas), subyacen también en los planteamientos liberales españoles ${ }^{4}$; sin embargo, ni son las únicas fuentes de influencia ni los legisladores de Cádiz desaprovecharán la ocasión para presentar como «reordenación» de lo propio lo que realmente es el fruto de los tiempos y de las «luces».

La escolástica española y la propia realidad monárquica del tiempo de los Austrias permitirán a los liberales difuminar la imagen revolucionaria de las nuevas teorías francesas que, con una oportuna relectura histórica, podrán ser presentadas como herencia de la historia patria. Ahora bien, si ello pudo ser extraordinariamente útil en los momentos en que se decidía sobre la Constitución, no fue suficiente para evitar la permanente sospecha de «afrancesamiento» (lo que en plena guerra podía considerarse sinónimo de traición) del texto que ha permitido prolongar la polémica ideológica y política sobre dicha Constitución hasta nuestros días. La preocupación por las raíces políticas de la Constitución

${ }^{2}$ F. TOMÁS Y VALIENTE ya subrayaba las extraordinarias dificultades del historiador para entender exactamente el desarrollo de las ideas que llegan a confluir en el texto constitucional no sólo por las incertidumbres y posibles confusiones derivadas de la multiplicidad de fuentes ideológicas, sino también por la interesada desfiguración y/u ocultación de las mismas por sus propios defensores [(2003). Genesi di un costituzionalismo euro-americano. Cadice 1812, Milano, Giuffrè].

${ }^{3}$ Es significativa la forma pragmática en que los americanos tratan de resolver el problema de la organización social y el establecimiento de instituciones sin la planificación teórica que sí se lleva a cabo en Francia.

${ }^{4}$ Cfr. entre los diversos trabajos de A. TORres Del Moral el titulado «1812: Recepción de los principios básicos del constitucionalismo» (en prensa) que recoge su ponencia en el Congreso Internacional «Los orígenes de las Cortes de Cádiz. Su influencia en las independencias latinoamericanas» que tuvo lugar en Valencia los días 29 y 30 de noviembre de 2010. 
pesará a lo largo de nuestro constitucionalismo como si fuera más decisivo saber de quién procede un texto que lo que el texto dice o, incluso, la eficacia del mismo ${ }^{5}$.

Planteado así el problema, nos proponemos llamar la atención sobre alguna de las paradojas que arroja nuestro primer constitucionalismo que tendrá consecuencias en todo el movimiento constitucional posterior:

En primer lugar, la representada por el éxito interior y exterior de una Constitución que, sin embargo, en la vida política española va a representar las aspiraciones de un o unos grupos políticos sin que se haya podido defender nunca como lo que realmente fue: la construcción del Estado Constitucional a partir del cual, y en su seno, habían de caber las distintas manifestaciones ideológicas.

En segundo lugar, y por lo que se refiere a la Monarquía, la Constitución de Cádiz realizó el cambio mas decisivo en la conversión de la Monarquía como forma de Estado a órgano del mismo y, por consiguiente, elemento importante pero uno más de entre los que, en su conjunción, podrían ir conformando diversas formas de gobierno; también resulta curioso en este segundo aspecto que, siendo conteste la doctrina en la consideración de la importancia de dicho cambio de concepción de la Monarquía, no se acierte a encuadrarlo en el más amplio cambio del Estado ${ }^{6}$.

5 Justamente esa cuestión de la «autoría» de la Constitución acabará enquistándose a lo largo del siglo XIX español durante el cual ninguna de las Constituciones va a considerarse legitimada por todos los grupos políticos y sociales, viviendo siempre marcada por la ideología del grupo que le dio soporte.

${ }^{6}$ Las razones son sin duda muy complejas y nos llevarían hasta la discusión sobre el papel de la Teoría del Estado en nuestro viejo Derecho Político. La bibliografía es densa, como se sabe, en lo que se refiere a la historia política y a la historia social de nuestro siglo XIX. La historia constitucional es en buena parte historia de las diversas Constituciones y la manualística responde en cada caso a la Constitución vigente del momento aunque es justamente en la manualística donde podemos ir reconstruyendo la Teoría del Estado y, en concreto, para el caso de Cádiz, a partir de los primeros Catecismos en los que se explica la Constitución entre los que destaca el de R. SALAS (1821). Lecciones de Derecho Público Constitucional para las Escuelas de España, Madrid, Imprenta de D. Fermín Villalpando. Sin embargo, lo que tratamos de decir en el texto es que ha faltado en la historia constitucional española el intento de describir el Estado Constitucional para conocer y comprender mejor las diversas instituciones que no obstante sí han merecido atención monográfica por parte de la doctrina. Justamente esa necesaria consideración de los fenómenos constitucionales decimonónicos desde el Derecho Público que ellos mismos iban construyendo sí ha empezado a realizarse recientemente por la escuela de Oviedo. Por todos, A. LARIO (2005). «Historia y Monarquía. Situación historiográfica actual». Historia Constitucional [en línea], núm. 6. [Consulta: 22 de junio de 2011]. Disponible en web: http://www.seminariomartinezmarina.com/ojs/index.php/historiaconstitucional/article/view/86/72. 
Ciertamente, si alguna institución se vio profundamente transformada fue la Monarquía pues es su cambio radical el que comporta y permite la aparición del nuevo Estado Constitucional (no en vano éste sólo será posible en otros escenarios con la radical desaparición de aquélla). En este sentido, la pervivencia del cambio no podía depender sólo de una perfecta estructuración teórica realizada por los juristas, requería de la colaboración de la Corona y del previo pacto político que no tuvo lugar. En lo que se refiere a la posición del tan esperado y deseado Fernando VII, de quien se esperaba la adecuación de la institución a los nuevos tiempos, el proyecto habrá de esperar hasta su muerte tras el fracaso del segundo intento representado por el Trienio. El pacto político se sustituyó por la manipulación de la institución monárquica; desde el momento en que la Monarquía diera nombre a alguno de los incipientes partidos (en realidad, aún, grupos de intereses) o que uno de estos se erigiera en valedor de la Monarquía, la construcción estatal de Cádiz ya no podría sostenerse teniendo que reconstruir, como así fue, el Estado «a retazos», en forma lenta y siempre discutida, cuyos resultados sólo se empiezan a percibir a fines del siglo XIX ${ }^{7}$.

\subsection{El primer constitucionalismo español. Significación política y jurídica}

El constitucionalismo liberal entra en España por la puerta grande con un texto que supera ampliamente la desafortunada propuesta napoleónica de Bayona. No le falta razón a De Esteban cuando subraya que España recibió tempranamente los aires del constitucionalismo liberal revolucionario situándose con el texto de 1812 entre los cinco primeros países del mundo en poseer una Constitución escrita ${ }^{8}$. Aquella primera Constitución fue ejemplo y estímulo de movimientos constitucionales foráneos y mito constitucional ${ }^{9}$ entre nosotros al que

7 Cfr. R. SÁnChez Ferriz (2010). «El germen del Derecho Constitucional como disciplina». Revista de Derecho Político, núm. 79, págs. 27-60.

8 J. De Esteban (1998). «Estudio preliminar», en Las Constituciones de España, Madrid, Boletín Oficial del Estado - Centro de Estudios Constitucionales, págs. 29-43.

9 Recientes estudios historiográficos ponen de relieve hasta qué punto la Constitución de 1812 ha sido la más estudiada y debatida, tanto desde el punto de vista teórico, por el indiscutible valor de sus aportaciones (y básicamente por la divergencia de posiciones sobre su origen ideológico), como desde el punto de vista político en el que, junto a las positivas referencias ya aludidas, cabe hallar el reproche de quienes extraen de ella la causa de algunos males que perduraron todo el siglo. Cfr. J.-R. Aymes (2003). «Le débat ideológico-historiographique autour des origines françaises du liberalisme español: Cotès de Cádiz et Constitution de 1812». Historia Constitucional [en línea], núm. 4. [Consulta: 22 de junio de 2011]. Disponible en web: http://www.seminariomartinezmarina.com/ojs/index.php/historiaconstitucional/article/view/194/189. También, M. LORENTE. «Nación española e instrucciones americanas», en el libro de próxima publicación dirigido por R. SÁN- 
nunca se pudo retornar, y esto contribuyó, tal vez, a alimentar esa sensación de fracaso constitucional que nos acompañó todo el siglo XIX.

Más que por sus aportaciones doctrinales e institucionales, de interés para todo constituyente posterior, será a lo largo de todo el siglo XIX un estandarte ideológico y, por consiguiente, se le sitúa en una de las partes del conflicto sin que pueda ya representar el diseño del Estado Constitucional al que, en todo caso, y con extraordinario retraso, había que llegar. Si ello ha tenido indiscutibles efectos políticos en todo nuestro constitucionalismo, no menor ha sido el condicionamiento historiográfico, también influido por las lecturas ideológicas.

El entusiasmo que rodea la obra de las Cortes de Cádiz (y no sólo su Constitución) fue parejo a lo extraordinario del momento histórico que en España se vivía: en aquel periodo cuajaban sentidas aspiraciones de una burguesía que es muy incipiente (tanto como la economía y el comercio con altos niveles de atraso) ${ }^{10}$. Tales aspiraciones conviven con circunstancias internas y externas de carácter extraordinario; pero ni las aspiraciones burguesas estaban suficientemente extendidas o asentadas para pactar el cambio social que hubiera permitido la aplicación de la Constitución, ni este freno social (y el retraso institucional que ello suponía) fueron tampoco suficientes para interrumpir la lenta maduración de las ideas ilustradas.

Dicho de otro modo, pese a lo extraordinario de las circunstancias, pudieron manifestarse «institucionalmente» las ideas liberales gestadas medio siglo antes y que después seguirán latentes, esperando otra ocasión. Lo que sí pudieron hacer esas circunstancias reales, y creo que historiográficamente lo consiguen, fue enmascarar el fenómeno puramente «cultural»e «ideológico-político» dándole unos tintes populares ${ }^{11}$ y monárquicos que poco tenían que ver con la obra técnica y legislativa que se lleva a cabo por las Cortes.

El revulsivo emocional de un pueblo que se sentía invadido y privado de su familia real permite a algunos hablar del monarquismo puro en la España de la

Chez Ferriz y P. Garcia Trobat que recopilará las actas del Congreso Internacional «Los orígenes de las Cortes de Cádiz. Su influencia en las independencias latinoamericanas» ya citado.

${ }_{10}$ Curiosamente, una de las explicaciones que permiten entender cómo pudo una escasa minoría liberal imponer sus planteamientos al resto de los diputados en Cádiz es la presencia de todos ellos en una ciudad de reducidas dimensiones en que la labor de los liberales vino reforzada por el apoyo de la burguesía gaditana que «colaboró en el esfuerzo de romper el equilibrio a favor del elemento liberal progresista». Cfr. J. L. Abellán (1981). Historia Crítica del Pensamiento Español, tomo 5, Madrid, Espasa Calpe, pág. 114.

11 Pero el ambiente de cambio radical llegaba a todos los niveles sociales. «Poder civil frente al militar... enfrentamientos de la alta y baja nobleza, del clero superior y el inferior, burgueses frente a nobles, plebeyos frente a ilustrados. En el cuerpo de lo que la Constitución legal hablaba de estamentos se habían enfrentado hombres y grupos, con el nacimiento de las clases. En fin, una sociedad que muere y otra que alumbra» [D. SEvilla ANDRÉs (1974), pág. 34]. 
primera revolución liberal pero una cosa es la participación del pueblo en el levantamiento y en la guerra y otra su nula presencia en la obra legislativa; en todo caso, sí hay sentimientos monárquicos en el levantamiento pero no se lucha por la Monarquía conocida sino por la alternativa que representa (supuestamente) el acceso al Trono del Príncipe de Asturias (Fernando VII). Es decir, incluso en la percepción de ese pueblo que pronto perdería su protagonismo (con el final de la guerra), la Monarquía (esperada) de «El Deseado» no era ya la misma que poco antes había repudiado por sus abusos: el mismo pueblo que se levanta contra Carlos IV y le hace abdicar en su hijo Fernando VII no espera de éste un régimen de absolutismo.

Por ello, el carácter popular del cambio también debe ser matizado pues una cosa es la propia concepción ilustrada, y revolucionaria, que cuaja en la idea de soberanía nacional y otra muy distinta la concreta actuación popular que, con ser importante en los actos de Aranjuez, no permite extraer directamente (de ninguno de los motines que acompañan las últimas horas de la Monarquía absoluta, el de Esquilache o Aranjuez, ni de todos ellos en conjunto) resultados jurídicos plasmados en la Constitución de 1812, aunque sí son indicios, entre otros, que denotan el ambiente de crisis generalizada del régimen ya agotado (y en sus últimos años acuciado también por la quiebra fiscal). Las formulaciones constitucionales no se improvisan a la vista de la actitud popular aunque ésta sí confiere legitimidad a las teorías que desde atrás han ido madurando.

En última instancia, lo que muere en Cádiz es la legitimidad tradicional que hasta entonces había dominado toda la vida política. En este sentido, no cabe desconocer que aun sin ser, como hemos dicho, un fenómeno propiamente «popular», sí se halla muy difundida, ya en los últimos años de la Monarquía ilustrada, la nueva fuerza social que, bajo el nombre de opinión pública, opina y debate (y somete a juicio) lo que hasta entonces habían constituido las bases intangibles del antiguo régimen. La opinión pública que años atrás se ha instalado en los salones y en las nuevas «sociedades ${ }^{12}$ » no sólo comporta la posibilidad de debatir sobre lo tradicionalmente intangible, es un nuevo cauce de expresión social que se superpone a los tradicionales para, progresivamente, abrir los debates a toda la sociedad ${ }^{13}$.

12 «Los canales tradicionales - Universidades, Ordenes religiosas - no sirven para expresar las nuevas ideas, y los elementos progresistas de la sociedad se ven forzados a crear nuevos medios de expresión. Así surgen las Academias, las Sociedades Económicas de Amigos del País... las tertulias y las reuniones sociales (soirées, fiestas galantes, teatros...)» [J.L. AbelLÁN (1981). Historia Crítica del Pensamiento Español, tomo 4, Madrid, Espasa Calpe, pág. 45].

13 Cfr. R. SÁnchez Ferriz (2007). «Significación histórica de las Libertades Públicas. Su configuración doctrinal en el período de la Restauración», en VV. AA., Derecho, Historia y Universi- 
Además, nuestro primer constitucionalismo tiene sobre otros la particularidad de poder presentarse como una recuperación de libertades tradicionales, de una parte porque así conviene a los liberales para contrarrestar el «pánico ${ }^{14}{ }$ que el recuerdo de los excesos de la revolución francesa aun generaba, pero, de otra, también, porque ciertamente en la historia de los reinos españoles existían precedentes dignos de ser considerados. Si no cabe afirmar que el Discurso Preliminar es fiel reflejo de la realidad histórica, no es menos cierto que sí contábamos con antecedentes en nuestros Reinos que, tanto en el campo de los derechos individuales, como en las relaciones institucionales entre el Monarca y las Cortes de los diversos Reinos, contaban con arraigo suficiente para haber entendido el absolutismo de los Borbones como un paréntesis o quiebra de las tradiciones ${ }^{15}$

dades. Estudios dedicados a Mariano Peset, tomo II, Valencia, Universidad de Valencia, págs. 617-632. El reciente libro de P. GARCiA TROBAT se halla cuajado de evidencias sobre la utilización de la opinión pública durante el periodo de las Cortes de Cádiz para difundir su obra y atraer adeptos a una posición, la liberal, en principio minoritaria [(2010). Constitución de 1812 y educación política. Madrid, Congreso de los Diputados].

${ }^{14}$ M. Friera Álvarez e I. Fernández Sarasola. «Contexto histórico de la Constitución española de 1812» [en línea]. [Consulta: 22 de junio de 2011]. Disponible en web: http://bib.cervantesvirtual.com/portal/1812/contexto.shtml.

15 M. Friera Álvarez e I. Fernández Sarasola. Ibíd. Recuerdan estos autores que cuando la guerra y la revolución estallan... «es entonces cuando se generaliza la apelación a la Constitución histórica española, rota definitivamente por el absolutismo despótico de Carlos IV. De ella se derivarán viejos conceptos con nuevos contenidos, como el de soberanía, derechos naturales, nación española, derecho de la misma a constituir su Gobierno, Monarquía moderada, Cortes, Constitución, etc. Los escritos sobre el tema, que ya existían, se multiplican: «[...] no puede privar a la nación del derecho que tiene de ser absoluta dueña y señora de elegir a su voluntad, y con el voto general de sus representantes, quien la haya de mandar, si por algún accidente finalizase la dinastía reynante [...] Teniendo jurado a su Príncipe Fernando, desde la edad de cinco años, con todas las formalidades de las leyes y constituciones de España, es la voluntad del pueblo todo, que el dicho Príncipe sea su señor y Rey»; «En Castilla exercía el Rey el poder executivo bastante limitado y el poder legislativo residía en las Cortes [...]. El derecho de imponer contribuciones, de hacer leyes y de reformar los abusos pertenecía a esta asamblea [...] En Aragón la forma de gobierno era monárquica como en Castilla, pero en una y otra parte el espíritu y los principios de su constitución eran republicanos. A las Cortes o a los Estados generales del Reyno pertenecía el exercicio real de la soberanía [.... E. En virtud de este juramento establecieron los Estados como un principio fundamental de la Constitución, que si el Rey violaba sus privilegios y sus derechos, la nación podía legítimamente deponerle de la soberanía y elegir otro en su lugar [...]. Por esto poco que hemos dicho vemos nuestra necedad en reírnos de los franceses, porque en su primera Constitución distinguieron y separaron el poder executivo del legislativo, reservando éste como inseparablemente inherente al cuerpo de la nación, y cediendo aquél a Luis XVI; nuestra necedad en reírnos de sus determinaciones y primeras leyes, no sabiendo que esto mismo hicieron sus antepasados, quando aquella nación no había perdido su libertad por la prepotencia de sus Príncipes; y que esto mismo hicimos nosotros por muchos siglos y se halla establecido en nuestras leyes más claro que la luz del 
que, sin perjuicio del entorno europeo favorable en los años de cambio de siglo, se entendió que definitivamente iba a quedar cerrado con el regreso de Fernando VII. No fue así, como los movimientos populares esperaban con su advenimiento, y habrá que esperar a su muerte.

De todo ello van a constituir un reflejo inigualable las Cortes de Cádiz, tanto por la peculiar forma «difusa» en que se reclama su constitución (por parte de las Juntas Provinciales) y se lleva a cabo, a modo de arriesgada aventura personal ${ }^{16}$ de cada uno de los diputados, como por la significación política de la obra que en solo dos años van a desplegar. Si políticamente están constituyendo el Estado Constitucional español, doctrinalmente están sentando las bases del Derecho Público contemporáneo (lo que no es muy frecuente en los cuerpos políticos representativos). No por conocido resulta innecesario recordar que las primeras Cátedras de Derecho Constitucional ${ }^{17}$ son fruto directo, y parte, de esa grandiosa obra de las Cortes.

Si se examina la labor previa a la Constitución y la que después (tras autoproclamar acabada su actividad «constituyente», para de inmediato continuar la labor ordinaria de las mismas) aún van a desarrollar, se observa que, siendo lo mas notorio el texto fundamental que elaboran, sólo la consideración de éste no es suficiente para valorar la aportación de aquellos años a la configuración política e institucional que se esta llevando a cabo cualquiera que fuera la vida posterior, tan sumamente breve, de la Constitución. En este aspecto nos detendremos ahora.

Pues, hay que repetirlo, bajo la superficie de las ya aludidas circunstancias extraordinarias que se viven en aquellos años, junto a los movimientos revolucionarios mas o menos populares y mas o menos monárquicos, el cambio de siglo trae consigo una nueva legitimidad que se opone a la tradicional desplazándola, una nueva ideología y en definitiva un nuevo Estado, liberal constitucional, que obligará a las instituciones tradicionales a reacomodarse o desaparecer. Las formas jurídicas del nuevo Estado van a trascender en todos los ámbitos de la

medio día [...]. Todo esto, y muchas cosas más que están haciendo, ¿no son cosas diametralmente opuestas a nuestras leyes fundamentales, a nuestra Constitución nacional y a nuestros derechos inalienables que los Príncipes han jurado mantener? [...]. ¿Puedes concordar este arbitrario procedimiento, y este abuso de poder con la libertad originaria, propia, esencial e imprescriptible de nuestra nación?».

16 J. Lorenzo Villanueva (1998 aunque escrita en 1860). Mi viaje a las Cortes, Valencia, Diputación de Valencia.

17 Justamente para dar cumplimiento al mandato constitucional contenido en el art. 386 se creó la primera Cátedra de Derecho Constitucional en Valencia, el 21 de septiembre de 1813, siendo su primer titular Nicolás Maria Garely. 
vida y también en la nueva institución monárquica que, no es de extrañar, resultaría desconocida para su propio titular.

Las bases ideológicas del nuevo Estado, curiosamente, se establecieron y fomentaron en las propias Cortes de los Monarcas ilustrados. Tampoco estos fueron ajenos a la preparación racional y técnica de las nuevas instituciones cuyos principios estructurales ya se sientan en la segunda mitad del siglo XVIII. La unidad de poder, necesaria en la próxima configuración del ordenamiento liberal, se preparó y ensayó por los propios monarcas ilustrados y por lo que se refiere a España se manifiesta en todos los ámbitos como radical aplicación del centralismo borbónico $^{18}$. Naturalmente, el despotismo buscó la unidad del poder (que hallaría especial efecto en el plano institucional ${ }^{19}$ ) en beneficio propio, pero al ha-

18 Entre tantos aspectos susceptibles de ser considerados, C. GARCIA MONERRIS y E. GarCia Monerris dedican un espléndido estudio a la cuestión de los señoríos que también las Cortes de Cádiz afrontan con el Decreto de 6 de agosto de 1811. El de los señoríos, dicen las autoras, es también un problema «constitucional» para el primer liberalismo español, entendiendo aquí por «constitucional» tanto la idea de un ordenamiento social y político peculiar, cuanto la más abstracta y formalizada de un código político. Y, por supuesto, «constitucional» será también el debate tardío en torno a qué hacer con el Real Patrimonio, estando como estaba directamente implicada una determinada concepción de la Corona y de la propia persona del Rey». Pero en todo caso, lo que importa a nuestros efectos es el enfoque de las autoras: «Lo que en realidad nos interesa destacar es que fue sobre la experiencia anterior y sobre sus resultados, sobre sus éxitos y limitaciones, sobre la que los distintos grupos y sectores en Cádiz elaboraron su estrategia y la nutrieron de determinados referentes [...]» [(2004) «La Nación y su dominio: el lugar de la Corona». Historia Constitucional [en línea], núm. 5 [Consulta: 22 de junio de 2011]. Disponible en web: http://www.seminariomartinezmarina.com/ojs/index.php/historiaconstitucional/article/view/98/84.

19 «Decaen o se suprimen los órganos de la administración que representan alguna autoridad al margen de los reyes: así los Consejos y las Cortes. Las Cortes, aparte de las de Madrid, Zaragoza y Barcelona de 1701 y 1702, se reúnen ya unificadas desde 1709; pero sólo serán convocadas seis veces a lo largo del siglo, y esto casi exclusivamente para jurar al heredero. De los Consejos desaparecen los de tipo territorial: Aragón, Flandes, Italia; extiende, en cambio, el de Castilla su jurisdicción a todos los dominios españoles. Otros Consejos, como el de Estado y el de la Inquisición, son heridos de muerte [...]. Cada vez administra el Rey más directamente y necesita para ello nuevos elementos que le ayuden en la tarea, y echa mano de los funcionarios, que habían sido siempre el medio más eficaz en que se apoyó la Monarquía absoluta. Aparecen así nuevos funcionarios: los ministros para la administración central, pues el antiguo secretario del Despacho universal se ha multiplicado para abarcar cinco — a veces seis_ carteras: Estado, Justicia, Guerra, Hacienda e Indias; y los intendentes para la administración territorial, a la vez que ésta es interferida también por la multiplicación de los corregidores y por la fiscalización central que se impone a los municipios, ya que por RR. CC. de 1751 y 1760 se ordenaba que sus cuentas fueran inspeccionadas por el Consejo de Castilla.

La creación de los intendentes, que de ser un puesto administrativo militar pasaron a constituir el fundamento de la administración provincial civil, y las reformas municipales de Carlos III 
cerlo así configuraban una estructura formal que habría de adquirir autonomía respecto de las primeras intenciones monárquicas en el mismo momento en que cuajaran los nuevos principios ideológicos modificando la legitimidad del poder. Porque en los años en que se reúnen las Cortes de Cádiz lo que ha madurado y busca la «ocasión social» para hacerse realidad es el liberalismo como doctrina política y el caso español no constituye una excepción en cuanto a la preparación ideológica y técnica que el despotismo ilustrado comportaba para su posterior establecimiento.

Además, el fermento ideológico ilustrado va a hallar circunstancias francamente propicias para su expresión en las mismas Cortes de Cádiz. La invasión francesa proporcionará la ocasión para presentar como movimiento nacional lo que ya venia cuajando en las mentes ilustradas y muy especialmente en la revisión metodológica y científica que el siglo XVIII alumbra ${ }^{20}$. La minoría liberal sabrá aprovechar bien las ocasiones que la peculiar reunión de Cortes le ofrece.

Pero sí fallaban los otros componentes que conformaron las revoluciones burguesas. Junto a la incipiente economía, la estructura social no era aun suficientemente sólida (o desgajada de los viejos esquemas impuestos por los privilegios de la aristocracia y la Iglesia) como para comprender que el desarrollo económico y el progreso no podían producirse sin las nuevas reglas de convivencia. Ello explica, y a la vez será resultado, de otro retraso considerable que también sufrimos en España: el referido a la concreta técnica jurídico-política con que se establece la estructura formal de los nuevos Estados, la codificación ${ }^{21}$. Pese a esta

procurando suprimir la perpetuidad de los cargos y los abusos consiguientes, así como introducir en la multiforme administración local española un principio de uniformidad, respondían al mismo deseo no solamente de controlar desde el gobierno la vida administrativa territorial y local, sino también de racionalizarla» [V. PALACIO ATTARD (1947). «El Despotismo Ilustrado español». ARBOR, núm. 22].

20 C. IgLesias (2005). El pensamiento de Montesquieu. Ciencia y filosofía en el siglo XVIII, Barcelona Círculo de Lectores.

21 «La profunda escisión entre Estado y Sociedad civil, perceptible sobre todo a lo largo del XIX, es asimismo el fundamento de la estrechísima relación que existe entre, en particular, el código por antonomasia, el civil, y la constitución, calificada ya entonces como Código Político. Y es que tal separación no sólo responde a criterios de economía legislativa, sino más bien a un reparto que se adecua exactamente a los requerimientos del modelo constitucional decimonónico, en especial en sus dos primeras etapas. De esta manera, en tanto que las constituciones se orientan a desarrollar la llamada parte orgánica, es decir, las instituciones estatales, limitándose a enunciar en la también denominada parte dogmática los deberes y los derechos individuales, desde ahora considerados como una concesión estatal que permite además consagrar la neta diferencia entre ciudadanos y hombres, el código civil lleva esta última materia hasta sus últimas consecuencias» [C. ÁLVAREZ Alonso (2003). «La legitimación del sistema. Legisladores, Jueces y Juristas en España (1910-1870 c. a.) (I)». Historia Constitucional [en línea], núm. 4, párrafo 49. [Consulta: 22 de ju- 
peculiaridad que sin duda contribuirá a la debilidad de la construcción estatal en España, si algún intento existe en ella antes del Decreto de Unificación de Fueros de 1868, es justamente el representado por la obra de las Cortes de Cádiz por más que todo ello no llegue a cuajar hasta el último tercio del siglo ${ }^{22}$.

\subsection{La Monarquía ilustrada en España}

La Monarquía en España conservaba sus formas absolutistas con Carlos III y Carlos IV por más que ambos, y fundamentalmente el primero, introdujeran elementos de progreso y de modernidad ${ }^{23}$ en la línea con los movimientos ilustrados de la Europa de la época. Solo que en esos nuevos elementos de la modernidad se contenían las bases del futuro Estado y, por ende, el fin de las Monarquías que contribuyeron a la difusión de las nuevas ideas.

Sevilla Andrés ${ }^{24}$ reivindicaba con fuerza las características propias del movimiento ideológico español que cuajó en Cádiz aun sin negar las influencias externas, tanto francesas como inglesas, pero vinculándolas al periodo precedente a las Cortes de Cádiz, en el que las ideas ilustradas habrían cuajado también entre nosotros. Tal vez, decía, si recuperamos la visión del Reinado de Carlos IV, tan

nio de 2011]. Disponible en web: http://www.seminariomartinezmarina.com/ojs/index.php/historiaconstitucional/article/view/193/171.

22 «Durante la mayor parte del Ochocientos, entre nosotros — pero es una opinión que podría hacerse extensiva a todas las formaciones políticas europeas - el Código por excelencia, el más importante, es siempre el político o Constitución. La práctica totalidad de los políticos profesionales —incluido Cánovas tras la Restauración — y la mayor parte de la doctrina estimaba al respecto que tal código debía responder y adaptarse a unos principios identificados con la Constitución Histórica, cuidadosamente elaborada $a d h o c$, de la que se resaltaba muy a propósito un falso concepto de unidad y una sociedad de individuos titulares de libertades, absolutamente semejante a la contemporánea...» (Ibíd., párrafo 84).

El problema, sin embargo, revestirá en el caso español mayor dificultad por la existencia de códigos o fueros particulares para algunos de los antiguos reinos que entorpecen e imposibilitan la unidad que otros Estados logran tempranamente: «...la peculiaridad del liberalismo y constitucionalismo hispánicos durante el XIX, consistente en compaginar la uniformidad con la diversidad. Es decir, la unidad política, representada por el derecho público, con la autonomía en los aspectos relativos al derecho civil, como regulador que es de las relaciones interindividuales y las bases, fundamentalmente económicas, de la sociedad» (Ibíd., párrafo 85).

23 A. ElORZA (1970). La ideología liberal en la Ilustración española, Madrid, Tecnos.

24 «D. SEvilla ANDRÉs me paraît être le précurseur des politologues actuels et historiens du Droit qui, partis à la recherche des sources multiples de la Constitution de Cadix, ont découvert, sur des points précis, des parentés avec des textes aussi bien espagnols que français (Montesquieu, l'Encyclopédie, le Contrat Social, Siéyès, cités par D. Sevilla) et anglais (Bentham, LocKe,... également cités par l'auteur)» [J.-R. Aymes (2003). Párrafo 131]. 
preñado de críticas, podríamos observar cómo en España, también después de Carlos III, se cultivan las artes y las letras, se fomenta la instrucción pública... «El espíritu del siglo, la doctrina de los filósofos, había entrado años atrás por los más diversos caminos»... «De los principios económicos a las creencias más tradicionales, todo se somete a juicio de residencia, y el ansia de saber, incluso para refutar los errores, pone de relieve una vasta erudición y, lo que es más importante, un notorio eclecticismo, especialmente en lo que a política se refiere ${ }^{25} »$.

Por ello, como Monarquía ilustrada, la española no escapa a las contradicciones que las nuevas inquietudes sociales comportaban. Es en el siglo XVIII cuando en el propio ambiente cortesano de los Monarcas «ilustrados» se inocula el germen del liberalismo «ideológico» de absoluta incompatibilidad con el Ancien Règime. Es tal el interés por las cuestiones sociales y políticas del momento que cambia el propio significado de la literatura de la que ya no van a formar parte solamente «las obras de los grandes creadores, sino los escritos de cualquiera que actúa como expositor de un grupo o de un estado de opinión. El no haber tomado esto en consideración es lo que ha devaluado tradicionalmente la cultura dieciochesca... En la época del despotismo ilustrado muchas veces no se sabe si es el Estado quien mueve la pluma de los ilustrados o son estos quienes se aprovechan de la buena disposición de aquél. Al menos llama la atención que casi todos los reformadores mas importantes del reinado de Carlos III ocuparon cargos oficiales destacados: Jovellanos, Campomanes, Olavide, Cabarrús... ${ }^{26}$

En el caso español el cambio se va a personificar en el hijo de Carlos IV que, no en vano, abdica forzado por las circunstancias. Entre Carlos IV y Fernando VII, sin embargo, no existen acontecimientos políticos interiores tan decisivos como para llevar a cabo el cambio de régimen que ambos representan aunque sí son los años en que van cuajando las influencias doctrinales y revolucionarias de allende los Pirineos. Encontrar el apoyo popular no había de ser difícil, pero el cambio sólo se lleva a cabo cuando han madurado las ideas ${ }^{27}$. Tal vez por ello lla-

25 D. Sevilla Andrés (1974). Historia Política de España (1800-1973), Madrid, Editora Nacional, págs. 25-26. F. TOMÁs Y VALIENTE rastrea los mas destacados textos políticos europeos para poder llegar a deducir la hondura de las discusiones políticas, y en concreto sobre las leyes fundamentales o normas de gobierno, que sin duda se llevaban a cabo, también en España, entre los años 1766 y 1788 [(2003), págs. 35 y ss. y pág. 43].

26 J. L. Abellán (1981). Tomo 4, pág. 45.

27 Lo que sí se ha ido extendido es la convicción de que estamos ante un tiempo nuevo en el que la vieja Monarquía ya no tiene cabida, discrepándose sólo del modo y la intensidad en que habían de limitarse sus poderes tradicionales. Cfr. J. VArela SuAnCes (1987). «Rey, Corona y Monarquía en los orígenes del constitucionalismo español: 1808-1814». Revista de Estudios Políticos, núm. 55, pág. 128. 
ma la atención sobremanera que en un cambio de siglo (y de reinado) sólo significado por alguna revuelta popular (el Motín de Esquilache en 1766 o el de Aranjuez en 1808), hicieran falta tan sólo unos pocos años, por lo demás en plena guerra con el francés, para dar a la luz pública el diseño de un nuevo Estado ${ }^{28}$ tal como, según vamos a ver, lo llevaron a cabo las Cortes de Cádiz.

\subsection{La herencia de la Ilustración en la obra de las Cortes de Cádiz}

En efecto, en los últimos años de la Monarquía ilustrada se han introducido los principios del nuevo Derecho Público que, como se ha visto, se recogen en Cádiz más o menos tamizados con el recuerdo de las libertades tradicionales. Pero lo más curioso en nuestra particular experiencia española es que se diseñan las máximas instituciones del Estado sin que se logre realizar la previa estructura de unidad jurídica estatal que también se difundió en los mismos años, aun de Monarquía ilustrada, y que dará paso al desarrollo capitalista paralelamente al nuevo Estado Liberal. La continuación de la obra iniciada por la Ilustración en punto a la construcción de la estructura estatal mediante la ya referida técnica codificadora resultaba decisiva en el Continente en el que los nuevos Estados liberales habían de «reconstruirse» jurídicamente, cosa que no pueden imitar del caso ingles que tradicionalmente ha ido cimentándose sobre el common law. El fenómeno de la codificación contribuye a la unidad jurídica que fortalecerá la idea del Estado, dentro del cual la Monarquía ira acomodándose en formas diversas según las circunstancias. Así, el proceso de industrialización y de desarrollo del capitalismo contará, de una parte con la seguridad del tráfico mercantil y, de otra, con las garantías suficientes para los derechos civiles de la clase que lo sustenta, la burguesía.

No así en el caso español. El extraordinario retraso del fenómeno codificador, tal vez parejo al del desarrollo de la burguesía, impide el asentamiento de un Estado respecto del cual la institución monárquica podría haber evolucionado por sí misma. Tal es la razón por la que el doctrinarismo cubre prácticamente todo nuestro siglo XIX salvo en los cortos periodos en que el progresismo intenta imponerse y, al tiempo, introducir la unidad de códigos que, sin embargo, sólo se acabará de implantar con la Restauración. Las Cortes de Cádiz sí lo intentaron

28 Resulta llamativo que con todo el entusiasmo despertado por el texto constitucional (un documento político de renombre no sólo por sus contenidos sino por la influencia que desarrollaría en Europa y en América, oímos permanentemente desde los mas diversos foros) no es fácil encontrar en la nutrida historiografía una determinación clara de lo que aporta, en particular en España, o, mejor dicho, lo que su promulgación significa, que no es otra cosa que el establecimiento, la construcción o constitución de un Estado totalmente nuevo. 
aunque las dificultades que previamente habían frenado el proceso seguían pesando en extremo. En todo caso, las Cortes sí ofrecen una completa idea de reformas tanto sociales como políticas de las que la Constitución es sólo su fruto más destacado. Con el Decreto de 24 de septiembre de 1810 se formalizan, juridificándose, toda una serie de actos previos a la reunión del cuerpo legislativo que, desde entonces, emprende una serie de medidas capaces por sí solas de transformar la sociedad. Así, Sevilla Andrés subrayaba la seriedad de la transformación emprendida tanto en el plano político como en el social. Por lo que se refiere al primero, junto al ya mencionado Decreto de 24 de septiembre, y al Reglamento para el Gobierno Interior de la Cámara (de 21 de noviembre de 1810), se destaca la ordenación de la Regencia o poder ejecutivo realizada el 16 de enero de 1811 con carácter provisional hasta la dictada el 26 de enero de 1812. Se crearon las Juntas de Provincia por el Decreto de 18 de marzo de 1811, que debian ser «el conducto por donde el Gobierno comunique a los pueblos las órdenes gubernativas y cuantas providencias estime conveniente dirigirles para la defensa de la Patria» debiendo ocuparse de la administración, de la formación del censo, del establecimiento de escuelas... ${ }^{29}$.

En lo que a la reforma social se refiere no pueden dejar de mencionarse los decretos por los que se defiende la condición igual de los españoles, ya sea para proclamarla entre españoles peninsulares y ultramarinos (Decreto de 5 de octubre de 1810) o para eximir de pruebas de nobleza a quienes desearan ser admitidos en los Colegios militares (Decreto de 17 de agosto de 1811) así como la defensa de la libertad frente a las trabas tradicionalmente impuestas; el Decreto de abolición de los señoríos (de 6 de julio de 1811) y el de abolición de los gremios junto a la significación burguesa de libertad de actuación de la propiedad comportan también la eliminación de viejas ligaduras vasalláticas y la proclamación de la capacidad individual. El Decreto sobre libertad de imprenta (de 10 de noviembre de 1810) y la declaración de incompatibilidad del mantenimiento del Santo Oficio con la Constitución (Decreto de 22 de febrero de 1813) permiten completar estas pinceladas sobre la obra reformadora de las Cortes de Cádiz que sólo perduraría hasta el regreso de Fernando VII.

El rechazo de su establecimiento por el propio Rey no puede, sin embargo, borrar la doble significación de la obra de las Cortes; en primer lugar, que las ideas que éstas reflejan en sus medidas legislativas no son improvisadas ni mera imitación francesa y, por consiguiente, buscaran nuevos cauces de expresión ${ }^{30}$; en se-

29 D. Sevilla Andrés (1974), pág. 60.

30 Cualquiera que sea la adscripción (afrancesada o españolista) de los autores de la obra de Cádiz, es lo cierto que ésta representa la ruptura de la concepción monárquica hasta entonces vigen- 
gundo lugar, que en la medida en que se ha dado vida a una concreta forma de Estado Constitucional, éste se ha desprendido de la idea monárquica e inicia a solas una andadura a la que habrá de adaptarse la institución monárquica.

La experiencia gubernamental de un período tan poco progresista como el del Estatuto Real es buena prueba de lo que decimos pues, como magistralmente recordaba Tomás Villarroya, viene a demostrar que por encima, y sin perjuicio de lo que el texto fundamental establezca, la vida política camina hacia el parlamentarismo en el que la Corona habrá de ir buscando su acomodo sin que las viejas formas puedan ya encontrar espacio político alguno. «Después del Estatuto la Corona continuó siendo formalmente lo principal del Estado; lo continuó siendo también para el común de las gentes; pero dejó de encarnar integramente el Estado, dejó de concentrar en sus manos todos los poderes del mismo y tuvo que compartirlos con las instituciones creadas o restauradas por aquel documento $^{31} »$.

Ciertamente, Fernando VII, aun pretendiendo retomar en 1814 el régimen de sus antecesores, no logra desenterrar las semillas del liberalismo, sembradas por las Cortes de Cádiz, que revivirán en el trienio y, aunque ya muy matizadas pero en lenta maduración, en el reinado de su hija Isabel. Así, por concluir, entre los reinados, de Carlos IV y de Fernando VII (con toda la lentitud de su larga duración), es donde podemos ver, aun con altibajos importantes, el cambio de significación de la Monarquía al que nos referimos en el título del epígrafe.

\section{LA MONARQUÍA EN EL ESTADO CONSTITUCIONAL QUE EN CÁDIZ SE ESTABLECE}

Tal vez la que podríamos considerar principal lección de Cádiz sea el hecho de que el Estado se sobrepone, definitivamente, a la Monarquía. La cuestión, a partir de entonces será cómo encajar la institución en el nuevo Derecho Público siendo que las experiencias pasadas nos presentan una institución radicalmente incompatible con los principios del Derecho Público. Ni que decir tiene que lo que Cádiz dejaba por hacer a los juristas posteriores era justamente hallar ese acomodo conformando la teoría del poder ejecutivo del mismo modo que el pri-

\footnotetext{
te con efectos definitivos: por mas que se vuelvan a vivir períodos de pretendido absolutismo (a la vuelta de Fernando VII, o tras el Trienio), por más que muchas de las facultades de las Cortes se devuelvan a la Corona (como en el Estatuto real), nada puede volver a ser igual por que todos estos intentos de vuelta al pasado aparecerán deslegitimados.

31 J. Tomás Villarroya (1968). El sistema político del Estatuto Real (1834-1836), Madrid, Instituto de Estudios Políticos, págs. 142-143.
} 
mer constitucionalismo liberal (la Constitución del 12 y aquí sí, también, la francesa) dejó configurada la del poder legislativo. Sólo que en nuestro caso resultó mas compleja la obra de determinación de estos dos poderes u órganos porque, en la ausencia del Rey, las Cortes van a personificar esa unidad de poder necesaria también en el nuevo orden. Tal vez por ello mismo la actividad de las Cortes, en lo que se refiere a la institución monárquica, requiere una doble lectura: de una parte, lo que «normativizan» en el texto constitucional teñido de recelos hacia la institución, y, de otra, lo que las propias Cortes realizan como centro unitario de poder. Ello es prueba de que no ignoran lo que después habrá de ser la Jefatura del Estado por más que, entre el recelo al monarca y lo excepcional de la situación de ausencia, y por consiguiente de vacío de poder, son conscientes de la impropiedad de las funciones que por sí mismas están ejerciendo (en particular las de carácter simbólico inherentes a la unidad estatal, propias de la Jefatura del Estado) y no pudiendo «normativizar» la realidad excepcional en que viven, optan por silenciar esas facultades subsumiéndolas en un «unitario poder ejecutivo» que, así, contiene una contradicción: al tiempo que es, y ha de ser, fuerte, se halla permanentemente tutelado y/o controlado por las Cortes que siquiera liberan las funciones que con el tiempo serán las más propias del Jefe del Estado.

Dando por sentado que la Monarquía pasa a ser «un poder constituido» más, la diversidad de sus poderes y sus formas ${ }^{32}$ resultan accidentales respecto de la centralidad de la cuestión que se acaba de subrayar. Por ello, el resto del siglo XIX nos presentará formas diversas de ejercicio de las funciones regias. Encontraremos a partir de entonces ensayos de vuelta al fortalecimiento del poder del Monarca (1845) y ensayos de reducción de sus funciones en términos de Monarquía constitucional e, incluso, parlamentaria (1869, en lo que se refiere al texto, por la imposibilidad de experimentar el sistema en la practica, y la experiencia constitucional, bajo la Constitución de 1876, tanto de Alfonso XII como de la Regencia a su muerte) pero en unos y otros casos nada se viene a innovar doctrinal y jurídicamente que no este ya previsto en el sistema institucional gaditano ${ }^{33}$.

32 Caben desde luego muy diversas manifestaciones de la institución, ya sean derivadas de la concepción general de cada régimen, ya por sus concretas relaciones con las Cortes. Así, por ejemplo, si atendemos a la configuración de la Cámara Alta podremos observar cómo en los momentos de mayor conservadurismo como los representados por la vigencia de la Constitución del 45, la Corona no goza de mayor libertad ni competencias que en otros de corte liberal como el regido por la Constitución de 1837.

33 Es cierto que la Monarquía doctrinaria va a ocupar buena parte de la experiencia constitucional del siglo pero no por duradera deja de ser una transacción pasajera con la que, a lo sumo, se podía llegar a la Monarquía constitucional cuya práctica parlamentaria dependería exclusiva- 
En efecto, a medida que la Monarquía deja de ser identificada con el Estado y pasa a representar el poder ejecutivo, todo cambio en concretos elementos del sistema político incidirá en la institución provocando cambios en su significación y papel dentro del Estado; hasta tal punto ello es así que sin duda alguna la Monarquía es derrotada en España en dos ocasiones (1868 y 1931) justamente por la confusión de sus propios titulares que, no sabiéndola mantener al margen del juego político, y por consiguiente en el papel institucional que le es propio a partir del establecimiento del Estado de Derecho, se manifiestan como parte de los intereses políticos representados por los partidos del momento.

No en vano, Jellinek ${ }^{34}$ distinguía entre las formas del Estado monárquico y las formas de la Monarquía; interesa ahora recordar la última de las que el maestro alemán considera formas ${ }^{35}$ del Estado monárquico: el monarca como miembro del Estado y órgano del mismo, por que «sólo cuando se concibe [al Estado] como una unidad interior que se apoya en sí misma, es cuando puede acompañar a la concepción del Estado la del monarca como miembro del mismo». El primer intento de constituir esta unidad obedece a legistas y canonistas que entendieron el imperio como asociación de personas, aunque la desviación absolutista acabe desfigurando el resultado. El segundo intento se apoya en la soberanía del pueblo y división de poderes, considerando al monarca como órgano dotado de poder limitado y al pueblo como sujeto primario del poder del Estado...

Es justamente en esta reflexión de Jellinek sobre el tercer tipo de Estado monárquico (que, queramos o no, se establece paradójicamente en la Constitución de Cádiz para un Rey que ha conocido en su padre la forma despótica de la Monarquía) donde se requiere la construcción de la teoría del poder ejecutivo que, mientras la Monarquía perviva, habrá de hacerse a caballo entre el discurso jurídico propio del Derecho Público moderno y, por consiguiente, en coherencia con la del poder legislativo, y la conservación de símbolos anejos a la tradicional con-

mente del talante personal de los monarcas, tal como ocurrió en las dos experiencias que se acaban de aludir del largo periodo de vigencia de la Constitución de 1876. Sólo en Cádiz se plantea tempranamente el esquema que, constituyendo como se ha dicho supra el Estado Constitucional, permitirá que la Monarquía persista con él a condición que se adecue a las distintas formas gubernamentales del Estado en las que la reserva de la Jefatura del Estado siquiera será incompatible con la forma de Estado democrática.

${ }^{34}$ G. JellineK (1915). Teoría General del Estado, traducción de la segunda edición alemana y prólogo de Fernando de los Ríos Urruti, Madrid, Librería General de Victoriano Suárez, págs. 378 y ss.

35 a) El monarca considerado como Dios o como representante de la divinidad, obviamente con multitud de formas a lo largo de la historia. b) El monarca como propietario del Estado... En este caso, como en el primero, el monarca es exterior al Estado. "Este es, respecto de él, objeto, o como en la concepción germánica, un sujeto separado del Monarca...»; y c) El monarca como miembro del Estado y órgano del mismo. 
cepción monárquica. Seguramente el choque de concepciones resultaba excesivo ${ }^{36}$ para su pacifica aceptación en la época que se estudia pero la aceptación del nuevo diseño estatal conllevaba inevitablemente la transformación de la institución monárquica en la forma como el texto constitucional lo hizo tal como enseguida vamos a ver. «La nota esencial al monarca es la de representar el poder supremo del Estado, esto es, aquel poder que conserva a éste y le pone en movimiento... Sólo en el sentido de que la organización del Estado es hoy legal, puede considerarse que la ley necesita ser el contenido de la voluntad del monarca, si bien de una manera permanente ha de considerarse como fruto de la voluntad del legislador. Sólo en este sentido se puede hoy afirmar que el poder del Estado está contenido potencialmente en el monarca; claro es, que este monarca no es el monarca real vivo, sino la institución abstracta».....37.

En lo que ahora importa, no cabía siquiera la posibilidad de concebir esa abstracción propia de la institución porque (aquí sí las circunstancias de la realidad son muy decisivas) la revolución, en lo que tiene de popular, se hace en defensa de los derechos dinásticos de una concreta persona. Tal vez es ésta la principal contradicción entre las ideas liberales que se defienden en Cádiz y su plasmación en una estructura institucional moderna, propia de un Estado de Derecho, que por fuerza ha de ser general sin hacer acepción de persona alguna. Más aséptica en este sentido, la Constitución francesa no tendrá inconveniente en mostrar la crudeza de la situación en que va a quedar la Monarquía tras la revolución. «De esta forma se vino a configurar un tipo de Monarquía que... se subordinaba al principio que proclamaba la soberanía nacional (lo que suponía excluir al Rey de toda participación en el proceso constituyente) y se incardinaba en un rígido sistema de separación de poderes, que traducía la desconfianza y el recelo existentes hacia el otrora omnipotente monarca absoluto, al que se relegaba a la posición de titular de un Ejecutivo de perfiles generalmente imprecisos, incomunicándolo con los otros poderes restantes» lo que justifica, según Porras, que Jellinek calificara esta Monarquía (nacional o republicana) de «República con un jefe hereditario ${ }^{38}$ »

36 Es cierto que quedan restos simbólicos de etapas anteriores pero adoptarlos con fuerza jurídica [por ejemplo, que es cabeza de la justicia... como también podemos ver hoy en nuestra Constitución vigente] nos llevaría, dice JELLINEK, a contradicciones irreconciliables. «Para el tipo de Estado moderno que hace de la totalidad del pueblo una unidad, el monarca sólo puede ser comprendido partiendo del Estado y considerándolo órgano del mismo. De ahí se sigue que el principio monárquico es de naturaleza puramente política...» [G. JELLINEK (1915), pág. 389].

37 G. JellineK (1915), págs. 390-391.

38 J. M. Porras Ramírez (1995). Principio democrático y función regia en la Constitución normativa, Madrid, Tecnos, pág. 71. 
De alguna manera, en las líneas anteriores hemos anticipado algunas conclusiones a las que cabe llegar desde el análisis de la configuración de la Jefatura del Estado monárquica en la Constitución de Cádiz, análisis que debe necesariamente partir de los dos principios estructurales que están presentes de forma transversal en el texto gaditano, la soberanía nacional y la división de poderes.

\subsection{La soberanía nacional}

Como es sabido, el artículo 3 de la Constitución de Cádiz proclama que «la soberanía reside esencialmente en la Nación, y por lo mismo pertenece a ésta exclusivamente el derecho de establecer sus leyes fundamentales». Nación que ha sido previamente definida como la reunión de todos los españoles de ambos hemisferios (art. 1).

Esta proclamación de la soberanía nacional presenta en la Constitución de 1812 una doble dimensión, externa e interna, que ya se encuentra en el Discurso Preliminar (DP, en adelante). Así, se declara en primer lugar la soberanía en su manifestación exterior de independencia nacional en el artículo 2 cuando se declara que «la Nación española es libre e independiente, y no es ni puede ser patrimonio de ninguna familia ni persona», impugnando así todo intento de fundamentar las renuncias de Bayona en una concepción patrimonialista de la relación entre la dinastía y la Nación, como ya se había anticipado en el Discurso Preliminar (VIII). Pero es el artículo 3 el que, como correlato de esa soberanía exterior, se refiere a su dimensión interna de poder constituyente al residenciar la soberanía en la Nación ${ }^{39}$ y declarar como consecuencia lógica su derecho exclusivo a establecer sus leyes fundamentales; en el mismo sentido el Discurso Preliminar fundamenta la soberanía de la Nación en el carácter electivo de la Corona en los antiguos reinos españoles para afirmar «como principio innegable que la autoridad soberana está originaria y esencialmente radicada en la Nación» (DP II) y considerarla como un derecho inherente y esencial a su existencia política, lo que conlleva en última instancia una afirmación implícita de la disponibilidad de la Nación soberana sobre la propia forma monárquica de gobierno.

Pero, como decíamos al comienzo, la afirmación de la soberanía nacional frente a cualquier atisbo de soberanía o cosoberanía regia impregna el conjunto del texto constitucional, desde la fórmula promulgatoria en la que el Rey se declara tal «por la gracia de Dios y la Constitución de la Monarquía española» y son las propias Cortes las que decretan y sancionan la Constitución, pasando por

39 En este sentido A. TORres del Moral (en prensa). Epígrafes dedicados a la soberanía según la Constitución española de 1812 y al poder constituyente popular. 
la intervención de las Cortes mediante decreto en la sucesión a la Corona, en la regencia y la tutela, en el matrimonio del Rey, de la Reina, del Príncipe de Asturias e Infantes y de su descendencia, hasta una regulación de la reforma constitucional en la que en ningún caso participa el Rey al limitarse su intervención a publicar el decreto de reforma y quedar excluido ${ }^{40}$ por tanto de la iniciativa y de la sanción previstas para el procedimiento legislativo ordinario. La rotundidad de la proclamación de la soberanía nacional coexiste, sin embargo con vestigios retóricos de la antigua legitimidad monárquica en el Discurso Preliminar cuando califica de «soberana» la reunión de la Nación y de su monarca en las sesiones de apertura y clausura de las Cortes (DP XVIII y XIX) — dando a entender que el Rey participa de la soberanía- y, especialmente, cuando finaliza pidiendo al Rey que, después de examinar, discutir y perfeccionar el texto constitucional, lo eleve «con su sanción a la naturaleza de ley fundamental» (DP XCIX) - lo que implica compartir con él el poder constituyente como sería propio de una Constitución pactada- La misma significación residual cabe atribuir a la expresión «prerrogativa» utilizada por los arts. 145 y 171 en relación con la sanción, dando a entender, como ha señalado algún autor ${ }^{41}$, la existencia de un fondo de poder que no se corresponde, a nuestro juicio, con la posición definida para el monarca en el texto constitucional.

\subsection{La división de poderes}

El principio de la división de poderes, formulado ya con toda claridad en el Decreto I, de 24 de septiembre de $1810^{42}$, es el otro pilar de la arquitectura constitucional de Cádiz. En el Discurso Preliminar la división de poderes se presenta como una exigencia funcional y organizativa derivada de la propia naturaleza de la sociedad, con independencia de su forma de gobierno del tal forma que la «autoridad soberana» de la Nación debe distribuirse «dividiendo su ejercicio en potestad legislativa, ejecutiva y judicial» (DP VIII). Se distingue, así, como ha

40 I. Fernández SARAsOla (2000), pág. 15.

41 M. MARTínez Sospedra (1978). La Constitución de 1812 y el primer liberalismo español, Valencia, Cátedra Fadrique Furió Ceriol, Facultad de Derecho, págs. 313-314.

42 «No conviniendo queden reunidos el poder legislativo, el ejecutivo y el judiciario, declaran las Cortes Generales y Extraordinarias que se reservan el ejercicio del Poder legislativo en toda su extensión. Las Cortes Generales y Extraordinarias habilitan a los individuos que componían el Consejo de Regencia para que, bajo esta misma denominación, interinamente y hasta que las Cortes elijan el Gobierno que más convenga, exerzan el Poder ejecutivo. La Cortes Generales y Extraordinarias confirman por ahora todos los tribunales y justicias establecidas en el Reyno para que continúen administrando justicia según las leyes». 
señalado Varela, entre la titularidad de la soberanía, esa «autoridad soberana» que corresponde originaria y unitariamente a la Nación, y su ejercicio que corresponde a los poderes constituidos ${ }^{43}$. Son los artículos 15, 16 y 17 de la Constitución los que, tras la conocida declaración del art. 14 según la cual «el Gobierno de la Nación española es una Monarquía moderada hereditaria», residencian las tres potestades mediante las que se ejerce la soberanía nacional, «la potestad de hacer las leyes [...] en las Cortes con el Rey», «la potestad de hacer ejecutar las leyes [...] en el Rey» $\mathrm{y}$ «la potestad de aplicar las leyes [...] en los tribunales establecidos por la ley». Hay, pues, tres poderes constituidos entre los que la Constitución distribuye las potestades estatales y que, en tanto actúen dentro de sus respectivas facultades, llevan a cabo actos de autoridad soberana, actos de soberanía. Puede hablarse así de la naturaleza derivada y no originaria de los poderes y facultades del monarca. Es cierto que la Constitución de Cádiz, a diferencia de la francesa de 1791 —artículos 2 a 5 del Título III—, no califica de delegados a los poderes constituidos y que el Discurso Preliminar sólo utiliza esa técnica con relación a la potestad jurisdiccional de los Tribunales (DP VIII, XI y XLIII), pero la misma significación cabe atribuir a la concepción de una autoridad soberana nacional originaria cuyo ejercicio se distribuye entre los distintos poderes y, en particular, la calificación del Rey como «depositario» (DP VIII y XIX) de la potestad ejecutiva frente a la atribución de la representación de la Nación exclusivamente a las Cortes (también a diferencia de la Constitución francesa de 1791 que califica de representantes de la Nación tanto al Rey como al Cuerpo Legislativo en el artículo 2 del Título III).

Existe así una capital distinción entre los órganos constitucionales de Cádiz. Mientras el Rey y los tribunales son respectivamente depositario y delegados para el ejercicio de sus respectivas potestades ejecutiva y jurisdiccional, la relación de las Cortes con la Nación soberana se configura, no en términos de delegación sino de representación. Las Cortes representan a la Nación soberana y por ello están en una posición especialmente cualificada en el sistema político gaditano ${ }^{44}$. Cabe aquí traer a colación el Decreto I, de 24 de septiembre de 1810, en el que los Diputados declararon que la soberanía residía en las Cortes Generales y Extraordinarias e inmediatamente a continuación, que se reservaban «el ejercicio del poder legislativo en toda su extensión»; si bien el artículo 3 de la Constitución residenció posteriormente la soberanía en la Nación y no en las Cortes, lo cierto es

43 J. VArela SuAnCES (1987), págs. 146-149. En el mismo sentido, I. Fernández Sarasola (2000). Págs. 16-17.

44 A. Torres del Moral (en prensa). Epígrafe dedicado a la división de poderes en Cádiz y a las Cortes de Cádiz como primer Parlamento español en sentido moderno. 
que esa especial proximidad, esa relación privilegiada del poder legislativo con la soberanía se encuentra también en el Discurso Preliminar cuando se afirma que la autoridad legislativa se reserva a la Nación bajo el principio de su soberanía e independencia (DP VIII); de ahí que tanto el Discurso Preliminar como la Constitución (arts. 27, 78 y 100) afirmen reiteradamente que las Cortes representan a la Nación, al sujeto titular de la soberanía, mientras que el Rey es tan solo depositario del ejercicio de una parte de la autoridad soberana, la potestad ejecutiva y coparticipe en la función legislativa; pero esta participación del Rey en la potestad legislativa no trae causa de considerarlo también representante de la Nación; el Discurso Preliminar justifica la participación del Rey en la legislación en la argumentación historicista ${ }^{45}$ del respeto a la Constitución antigua de España (DP VIII) y, en concreto, atribuye a la sanción regia una finalidad correctiva y depuradora (DP XXI), necesaria para templar las decisiones de un órgano deliberante numeroso en circunstancias accidentales y excepcionales. Se trata, pues, de un poder legislativo esencialmente atribuido a las Cortes y compartido con el Rey por razones históricas y de equilibrio y contrapeso de las facultades parlamentarias y que no se basa en la existencia de una representación dualista de la Nación en el binomio Rey-Cortes; por otra parte, el Rey tiene iniciativa legislativa (art. 171.14) que comparte con los Diputados (art. 132), el veto asociado a la sanción es tan sólo suspensivo y no absoluto (arts. 142-152) con dictamen previo del Consejo de Estado (art. 236) y, por último, promulga las leyes, encomendando su publicación al Secretario del Despacho respectivo (arts. 154-156).

Es precisamente esa concepción de las Cortes como «Cuerpo representativo de la Nación» (DP XVII), que se hace visible en la misma fórmula de juramento de los Diputados — exclusivamente referida a la religión católica, a la Constitución y al bien y prosperidad de la Nación (art. 117) y no al Rey- lo que explica la participación decisiva de las Cortes en el ejercicio de la potestad ejecutiva por el Rey y en la función de gobierno y dirección política, como puede verse al examinar las facultades del Rey y las restricciones a las que está sujeto.

Según el Discurso Preliminar, el Rey es el «jefe del Gobierno y primer magistrado de la Nación» en el que la Nación deposita «por medio de la Constitución» la potestad ejecutiva en su totalidad (DP XXIII); por su parte, el artículo 170 del texto constitucional declara, en su conocida formulación, que «la po-

45 Sobre el uso del historicismo en el constitucionalismo gaditano, vid. I. Fernández Sarasola (2000). «La Constitución Española de 1812 y su proyección europea e iberoamericana». Fundamentos [en línea], núm. 2, págs. 9-12. [Consulta: 25 de junio de 2011]. Disponible en web: http://www.unioviedo.es/constitucional/fundamentos/segundo/pdf/constitucion1812.pdf. 
testad de hacer ejecutar las leyes reside exclusivamente en el Rey, y su autoridad se extiende a todo cuanto conduce a la conservación del orden público en lo interior, y a la seguridad del Estado en lo exterior, conforme a la Constitución y a las leyes»; pese a esta concepción amplia y genérica del contenido del poder ejecutivo, en el Discurso Preliminar ya se pone de manifiesto la preocupación por tasar y delimitar con la máxima precisión («individualidad») las competencias regias y a ello responderá la enumeración de sus facultades «principales» — hasta dieciséis - en el artículo 171. Pero, a juicio del Discurso Preliminar estas facultades atribuyen al Rey un «inmenso poder»y autoridad por lo que se hace necesario establecer un elenco de restricciones a las mismas en el artículo 172, además de las limitaciones ya establecidas de forma dispersa a lo largo del articulado; así, la Comisión consideró «esencialísimo todo lo concerniente a las limitaciones de la autoridad del Rey» para evitar oscuridad y ambigüedades que den lugar a «las funestas alteraciones que tanto han desfigurado y hecho variar la índole de la Monarquía» y con este objeto pretendió señalar «con escrupulosidad reglas fijas, claras y sencillas» que determinaran «con toda exactitud y precisión» la autoridad de los tres poderes constituidos (DP XXIII y IX).

Así, combinando las facultades regias con las limitaciones ${ }^{46}$ impuestas a las mismas, podemos establecer el alcance de los poderes del monarca gaditano al que corresponden los siguientes:

1. Le corresponde la potestad reglamentaria ejecutiva («expedir los decretos, reglamentos e instrucciones que crea conducentes para la ejecución de las leyes», art. 171.1), pero no puede dictar reglamentos independientes ni tiene potestad ejecutiva respecto de los decretos de Cortes; por otra parte, son las Cortes quienes deben aprobar los reglamentos generales de Policía y Sanidad (art. 131.23).

2. Tiene el deber genérico de cuidar de la pronta y cumplida administración de la justicia (art. 171.2) que se administra en su nombre de la misma forma que en su nombre se encabezan las ejecutorias y provisiones de los tribunales superiores (art. 275); nombra a los magistrados de los tribunales civiles y criminales, pero a propuesta del Consejo de Estado (art. 171.4) y correspondiendo a las Cortes decretar la creación y supresión de las plazas (art. 131.9); asimismo, puede suspender, previo expediente y oído el Consejo de Estado, al magistrado contra el que se presenten quejas aparentemente fundadas, pero debe dar traslado inmediato al Tribunal Supremo para su enjuiciamiento (art. 253) y debe ser consul-

${ }^{46}$ Ibíd., págs. 20-23. 
tado por el Tribunal Supremo sobre las dudas interpretativas planteadas al mismo por los demás Tribunales pero sólo a los efectos de promover la declaración de las Cortes a quien corresponde la interpretación de las leyes (arts. 261.10 y 131.1)

3. Declara la guerra, previo dictamen del Consejo de Estado, y firma la paz, aunque debe dar cuenta documentada a las Cortes (arts. 171.3 y 236).

4. Provee todos los empleos civiles y militares (art. 171.5) si bien son las Cortes las competentes para crear y suprimir los oficios públicos (art. 131.9).

5. Concede honores y distinciones de toda clase, con arreglo a las leyes (art. 171.7) pero tiene prohibido conceder privilegios exclusivos a personas o corporaciones (art. 172. 9)

6. Manda el Ejército y la Armada y dispone de ellos y los distribuye a su conveniencia, pero las Cortes, a propuesta del Rey, fijan anualmente el contingente de tropas y el número de buques militares; nombra a los generales si bien son las Cortes quienes regulan su régimen disciplinario, económico y administrativo mediante las ordenanzas (arts. 171.8 y 9, 131.10 y 11 y 357-359); dispone de la milicia nacional dentro de cada provincia aunque necesita autorización de las Cortes para usarla fuera de los límites provinciales (art. 365). Corresponde a las Cortes conceder o negar la admisión de tropas extranjeras en el territorio nacional (art. 131.9)

7. Dirige las relaciones diplomáticas y comerciales con las demás potencias pero limitado por el consentimiento de las Cortes para concertar alianzas ofensivas y tratados especiales de comercio o que obliguen a dar subsidios a potencias extranjeras; asimismo, nombra a los embajadores y representantes diplomáticos (arts. 171. 10, 131.7 y 172.5 y 6). Requiere además del dictamen del Consejo de Estado para la celebración de tratados internacionales (art. 236).

8. Cuida de la fabricación de la moneda (art. 171.11) pero las Cortes determinan el valor, peso, ley, tipo y denominación de las monedas (art. 131.19).

9. Presenta el presupuesto general anual a través del Secretario del Despacho de Hacienda así como el plan de las contribuciones necesarias para sufragar los gastos (arts. 227, 341 y 343) y decreta la inversión de los fondos destinados a cada uno de los ramos de la administración pública (art. 171.12), según los gastos fijados por las Cortes quienes deben examinar y aprobar las cuentas de las inversiones (art. 131.12). Asimismo, decreta los pagos con el refrendo del Secretario del Despacho de Ha- 
cienda, expresando el gasto a que se destina su importe y el Decreto de las Cortes autorizante (art. 347). Los Secretarios le rinden cuentas de los gastos de sus respectivos ramos (art. 227).

10. Ejerce el derecho de gracia con arreglo a las leyes (art. 171.13)

11. Nombrar y separa libremente a los secretarios de Estado y del Despacho (art. 171.16), si bien las Cortes pueden hacer las variaciones que la experiencia o las circunstancias exijan en este sistema de secretarías del Despacho cuyo número se fijo en siete por la propia Constitución (art. 222).

12. Nombra al jefe superior del gobierno político de las provincias que presiden las Diputaciones Provinciales (arts. 324 y 325 ) y puede suspender a los vocales de las Diputaciones Provinciales en caso de abuso de sus facultades, pero debe dar parte motivadamente a las Cortes que adoptarán la decisión que corresponda (art. 336).

13. Presenta a las Cortes, a través del Secretario del Despacho de Hacienda, contribuciones alternativas a las que estime gravosas o perjudiciales (art. 343); son las Cortes quienes establecen anualmente las contribuciones e impuestos y aprueban su reparto entre las provincias (art. 131.13 y 15), prohibiéndose expresamente al Rey imponer por sí directa ni indirectamente contribuciones, ni hacer pedidos bajo cualquier nombre o para cualquiera objeto que sea sin que los hayan decretado las Cortes (art. 172.8).

14. Tiene prohibido expresamente disponer de parte alguna del territorio nacional (art. 172.4) y necesita el consentimiento de las Cortes para ceder o enajenar bienes nacionales (art. 172.7).

15. No puede disponer de su autoridad real ni de ninguna de sus prerrogativas y necesita el consentimiento de las Cortes para abdicar en su inmediato sucesor (art. 172.3) así como para contraer matrimonio, entendiéndose en este último caso si no lo solicitara que ha abdicado la Corona (art. 172.12). Tampoco puede ausentarse del Reino sin consentimiento de las Cortes, entendiéndose en tal caso que ha abdicado la Corona (art. 172.2).

Junto a las restricciones de la autoridad del Rey, la Constitución exige el refrendo de sus actos por los Secretarios del Despacho (arts. 225-229), refrendo que el Discurso Preliminar motiva en una doble necesidad: la irresponsabilidad del Rey para que pueda ejercer eficazmente el poder ejecutivo sin riesgo de altercados y enfrentamientos civiles que pongan en peligro la pervivencia de la propia Monarquía y, correlativamente, la necesidad de la contrafirma ministerial para «ha- 
cer efectiva la responsabilidad del Gobierno» (DP, XXIX) por las órdenes del monarca; así, la Constitución declara que «la persona del Rey es sagrada e inviolable» (art. 168) y dispone que «todas las órdenes del Rey deberán ir firmadas por el secretario del despacho del ramo a que el asunto corresponda. Ningún tribunal ni persona pública dará cumplimiento a la orden que carezca de este requisito» (art. 225). Pero este refrendo no da lugar a responsabilidad política de los Secretarios ante las Cortes sino tan sólo a una responsabilidad jurídica fundada en criterios de constitucionalidad y legalidad — «los secretarios del despacho serán responsables a las Cortes de las órdenes que autoricen contra la Constitución o las leyes, sin que les sirva de excusa haberlo mandado el Rey» (art. 226)_, correspondiendo a las Cortes la acusación — que conlleva la suspensión del Secretarioy la instrucción y enjuiciamiento al Tribunal Supremo (arts. 228 y 229).

Además del refrendo, el Rey requiere del dictamen del Consejo de Estado «en los asuntos graves gubernativos, y señaladamente para dar o negar la sanción a las leyes, declarar la guerra, y hacer los tratados» (art. 236), configurándose este órgano como la única instancia de consejo y asesoramiento al Rey. Los cuarenta consejeros que lo integran (cuatro eclesiásticos, cuatro Grandes de España y el resto notables distinguidos por su ilustración, conocimientos o servicios al Estado) son nombrados por el Rey, a propuesta de las Cortes en lista triple y son inamovibles salvo por el Tribunal Supremo por causa justificada (arts. 231-241).

Esta división de poderes responde, como se ha señalado por la doctrina, a una concepción rígida ${ }^{47}$ de separación cuasiabsoluta de los mismos. Ya en el Discurso Preliminar se afirmó que la separación de poderes es «indispensable»: «la experiencia de todos los siglos ha demostrado hasta la evidencia que no puede haber libertad ni seguridad, y por lo mismo justicia ni prosperidad en un Estado en donde el ejercicio de toda la autoridad esté reunido en una sola mano» (DP, VIII). Y el articulado constitucional vino a consagrar esa separación de poderes que se pretendió justificar no en razones abstractas de filosofía política, sino en la experiencia y en la tradición histórica española.

Así, por lo que se refiere a las relaciones entre el poder ejecutivo y el legislativo, la Comisión redactora dejó constancia de la dificultad de establecer los límites entre $\operatorname{ambos}^{48} \mathrm{y}$, como ya se ha dicho, argumentó la participación del Rey en las tareas legislativas en el historicismo y la sanción, en concreto, en el

47 Ibid., pág. 17.

48 «Los límites que se deben señalar, particularmente entre la autoridad legislativa y ejecutiva para que formen un justo y estable equilibrio, son tan inciertos, que su establecimiento ha sido, en todos tiempos, la manzana de la discordia entre los autores más graves de la ciencia del gobierno, y sobre cuyo importante punto se han multiplicado al infinito los tratados y los sistemas» (DP, VIII). 
contrapeso y moderación de los excesos asamblearios. Además de la iniciativa legislativa y la prerrogativa de la sanción y promulgación, hay que decir que el Rey se limita a asistir a la apertura y a la clausura de las Cortes — que en ningún caso serán diferidas aunque el Rey manifestare impedimentos- y a realizar un discurso en la apertura (que será leído por el Presidente si no asiste el monarca) al que el Presidente contesta en términos generales (arts. 121 y 123). Carece, pues, el monarca de la facultad de convocar las Cortes que se reunirán anualmente a fecha fija — «con el fin de evitar que el influjo del Gobierno o las malas artes de la ambición puedan estorbar jamás con pretextos o alargar con subterfugios la reunión del Congreso nacional» (DP, XVIII) — durante tres meses consecutivos, reunión anual que en el Discurso Preliminar se presenta como «un freno que constantemente [...] contenga [a la autoridad real] dentro de sus límites ${ }^{49}$ »; por otra parte, el Rey no sólo no tiene atribuida la disolución y suspensión de las Cortes sino que se le prohíbe expresamente «impedir bajo ningún pretexto la celebración de las Cortes en las épocas y casos señalados por la Constitución, ni suspenderlas ni disolverlas, ni en manera alguna embarazar sus sesiones y deliberaciones», señalando que quienes «le aconsejasen o auxiliasen en cualquiera tentativa para estos actos, son declarados traidores, y serán perseguidos como tales» (art. 172.1). Sí puede el monarca pedir a las Cortes que prorroguen sus sesiones un mes adicional (art. 107) y también solicitar a la Diputación Permanente la convocatoria de las Cortes extraordinarias «cuando en circunstancias críticas y por negocios arduos tuviere [...] por conveniente que se congreguen» (art. 162.3). Con el fin de asegurar «la absoluta libertad de las discusiones»(DP, XVIII) y evitar la influencia del Rey con su presencia en las deliberaciones, se prohíbe a las Cortes deliberar en su presencia (art. 124). Hasta tal punto llega la desconfianza en el monarca, reiteradamente presente en el Discurso Preliminar, que se prescribe expresamente que en la apertura y clausura de las Cortes el Rey entrará «sin guardia» y con la sola compañía de las personas determinadas por el ceremonial establecida por el reglamento del gobierno interior (art. 122). Se suaviza, no obstante, el rigor de la incomunicación física entre el Rey y las Cortes al permitir el artículo 125 que los Secretarios del Despacho puedan asistir e intervenir en las discusiones de las propuestas legislativas realizadas en nombre del Rey pero «cuando y del modo que las Cortes determinen» aunque no podrán estar presentes en la votación.

49 Así, se afirma que «el juntar Cortes cada año es el único medio legal de asegurarse la observancia de la Constitución sin convulsiones, sin desacato a la autoridad y sin recurrir a medidas violentas que son precisas y aun inevitables cuando los males y vicios en la Administración llegan a tomar cuerpo y envejecerse»; la convocatoria anual de Cortes se valora así como una forma de que la Nación esté «siempre viva y vigilante por medio de sus procuradores» (DP, XVII). 
Se establece, además, un régimen de rigurosas incompatibilidades entre el Ejecutivo y el Legislativo. Así, los secretarios del Despacho, los consejeros de Estado, y los empleados de la Casa Real, no podrán ser elegidos Diputados de Cortes (arts. 96 y 232) al igual que los Infantes de España (art. 205) y los Diputados, durante el tiempo de su mandato, no podrán aceptar (ni solicitar para otro) ningún empleo de provisión del Rey ni ascenso salvo de escala en su respectiva carrera; idéntica prohibición se establece para solicitar pensión o condecoración alguna del Rey durante el periodo de su mandato y el año siguiente a la finalización de sus funciones (arts. 129 y 130). Tampoco los empleados públicos de nombramiento gubernamental podrán ser elegidos Diputados de Cortes por la provincia en que ejercen su cargo (art. 97). Alcanzan también las incompatibilidades de los empleados del Ejecutivo al ámbito municipal de tal manera que «no podrá ser alcalde, regidor ni procurador síndico ningún empleado público de nombramiento del Rey, que esté en ejercicio», a excepción de los miembros de las milicias nacionales (art. 318).

La separación entre el poder judicial y los otros dos poderes del Estado es objeto de especial atención. Así, una de las razones que se dan en el Discurso Preliminar para la creación del Consejo de Estado es, además de no distraer a los magistrados en el ejercicio de la potestad jurisdiccional, «determinar con toda escrupulosidad, y conservar enteramente separadas las facultades propias y características de la autoridad judicial»(DP, XXX). La preocupación de la Comisión por la independencia del poder judicial se refleja en rotundas referencias en el discurso de Argüelles: «para que la potestad de aplicar las leyes a los casos particulares no pueda convertirse jamás en instrumento de tiranía, se separan de tal modo las funciones del juez de cualquiera otro acto de la autoridad soberana, que nunca podrán ni las Cortes ni el Rey ejercerlas bajo ningún pretexto»; si en circunstancias excepcionales puede admitirse la concentración temporal de los poderes legislativo y ejecutivo en una sola autoridad, no sucede lo mismo con la potestad judicial: «en el momento que ambas autoridades o alguna de ellas reasumiese la autoridad judicial desaparecería para siempre no sólo la libertad política y civil, sino hasta aquella sombra de seguridad personal, que no pueden menos de establecer los mismos tiranos si quieren conservarse en sus Estados». Las reminiscencias del pensamiento de Montesquieu son en este caso más que evidentes $^{50}$.

50 «Cuando el poder legislativo está unido al poder ejecutivo en la misma persona o en el mismo cuerpo, no hay libertad porque se puede temer que el monarca o el Senado promulguen leyes tiránicas para hacerlas cumplir tiránicamente. Tampoco hay libertad si el poder judicial no está separado del legislativo ni del ejecutivo. Si va unido al poder legislativo, el poder sobre la vida y la libertad de los ciudadanos sería arbitrario, pues el juez seria al mismo tiempo legislador. Si va uni- 
Desde estas premisas, la Constitución determina que «la potestad de aplicar las leyes en las causas civiles y criminales pertenece exclusivamente a los Tribunales» (art. 242) y prohíbe expresamente a las Cortes y al Rey ejercer en ningún caso las funciones judiciales, no pudiendo privar de libertad, ni imponer pena alguna a ningún individuo, bajo responsabilidad del Secretario del Despacho que firme la orden, y el juez que la ejecute por atentado contra la libertad individual, admitiéndose la expedición de órdenes de arresto sólo en el caso de que el bien y seguridad del Estado los exijan pero con la condición de puesta a disposición del detenido en cuarenta y ocho horas ante el tribunal o juez competente; de la misma forma, le prohíbe avocar causas pendientes, ordenar reabrir los juicios fenecidos y dispensar el orden y las formalidades del proceso señaladas por las leyes (arts. 172.11, 243 y 244). Asimismo, se reserva al Tribunal Supremo el enjuiciamiento de los magistrados contra los que se presenten quejas fundadas a cuyos efectos el Rey le dará traslado inmediato del expediente formado, aunque podrá suspenderle oído el Consejo de Estado (art. 253). Por último, cabe señalar que aunque la justicia se administra en nombre del Rey y las ejecutorias y provisiones de los tribunales superiores se encabezarán también en su nombre (art. 257), resulta llamativo que ello se fundamente en el Discurso Preliminar, no en la consideración del Rey como Jefe del Estado que represente la unidad de los tres poderes, sino en su condición de titular de la potestad ejecutiva, capaz, en cuanto tal, de imponer el cumplimiento de las decisiones judiciales $^{51}$.

\footnotetext{
do al poder ejecutivo, el juez podría tener la fuerza de un opresor. Todo estaría perdido si el mismo hombre, el mismo cuerpo de personas principales, de los nobles o del pueblo, ejerciera los tres poderes: el de hacer las leyes, el de ejecutar las resoluciones públicas y el de juzgar los delitos o las diferencias entre particulares» [MONTESQUIEU (1980). El Espíritu de las Leyes [en línea], traducción y preparación por M. BLÁzQueZ y P. DE VeGA, Madrid, Tecnos, Libro XI, Capítulo VI. [Consulta: 5 de noviembre de 2009]. Disponible en web: http://www.der.uva.es/constitucional/materiales/libros/Montesquieu.pdf.

51 «Aunque la potestad judicial es una parte del ejercicio de la soberanía delegada inmediatamente por la Constitución a los Tribunales, es necesario que el Rey como encargado de la ejecución de las leyes en todos sus efectos, pueda velar sobre su observancia y aplicación. El poder de que está revestido y la absoluta separación e independencia de los jueces, al paso que forman la sublime teoría de la institución judicial, producen el maravilloso efecto de que sean obedecidas y respetadas las decisiones de los Tribunales, y por eso sus ejecutorias y provisiones deben publicarse a nombre del Rey considerándole en este caso como el primer magistrado de la Nación» (DP, XLIII).
} 


\section{3. «Monarquía Moderada» y Monarquía Limitada}

Con lo dicho hasta ahora se puede reafirmar una valoración ya expuesta, nada novedosa por ser muy compartida por la doctrina pero que entendemos relevante para el estudio de la Monarquía gaditana: el Rey es un poder constituido ${ }^{52}$, al igual que los demás órganos constitucionales, y no participa en la titularidad del poder constituyente originario ni tampoco en el poder constituyente-constituido, en el poder de reforma de la Constitución. Además de lo que ya se ha señalado con anterioridad, pueden añadirse otros datos significativos a este respecto. por una parte, las restricciones a la autoridad del Rey contenidas en el texto constitucional están protegidas por la rigidez constitucional; señala en este sentido el Discurso Preliminar que «el Gobierno de España es una Monarquía hereditaria, moderada por la ley fundamental, sin que en las limitaciones que la modifican pueda hacerse ninguna alteración, sino en los casos y por los medios que señala la misma Constitución» (DP, XI), afirmación que equivale a negar la existencia de poderes de reserva en el Rey que éste pueda activar para modificar las limitaciones constitucionales de sus poderes por el procedimiento legislativo ordinario con su consiguiente concurso en forma de iniciativa legislativa y sanción. Por otra parte, las últimas y conocidas palabras del alegato de Argüelles ofrecen una imagen muy plástica de la naturaleza constituida de la autoridad real en Cádiz cuando pide a Fernando VII que le diga a la Nación que «hoy más que nunca debe redoblar sus esfuerzos para acelerar el suspirado momento de restituirle al Trono de sus mayores, que reposa majestuosamente sobre las sólidas bases de una Constitución liberal» (DP, XCIX in fine). Es decir, no es la Constitución la que reposa sobre el Trono como sería el caso de una Carta otorgada desde el principio monárquico sino el Trono el que reposa sobre la Constitución.

Si esto es así, hay que partir de esta exclusión del Rey de la potestad constituyente para tratar de esclarecer la naturaleza de la «Monarquía hereditaria moderada» proclamada el día de San José de 1812. Pues bien, coherentemente con lo dicho, la Monarquía moderada no puede identificarse a nuestro juicio con lo que comúnmente se entiende por una Monarquía limitada en sentido estricto $^{53}$, esto es, con un sistema político fundamentado en el principio monár-

52 A. Torres del Moral (en prensa). Epígrafes dedicados a la soberanía según la Constitución española de $1812 \mathrm{y}$ al poder constituyente popular.

53 Suele citarse como paradigmático de la Monarquía limitada el Preámbulo de la Carta francesa de 1814 del que se extractan los siguientes párrafos como los más significativos: «Se ha solicitado una Carta constitucional debido al estado actual del Reino; la hemos prometido y la publicamos. Hemos considerado que, aunque toda la autoridad ha residido en Francia en la persona del Rey, nuestros predecesores no han dudado en modificar su ejercicio según la diferencia de los tiem- 
quico $^{54}$ según el cual un Rey plenamente soberano autolimita su poder otorgando una Carta constitucional mediante la que la Asamblea o Parlamento colabora en el ejercicio de la función legislativa y se reserva para sí la potestad ejecutiva, pero que en cuanto órgano supremo del Estado es también el titular residual de todas aquellas competencias no expresamente atribuidas a otros órganos y goza de una presunción de competencia a su favor, de la competencia sobre la competencia. Entiende, sin embargo, Diego Sevilla que la atribución de la ejecución al Rey en términos de «potestad» en el artículo 170, demuestra el carácter originariamente constituyente del monarca ${ }^{55}$, y Martínez Sospedra considera que el Rey es el depositario de un fondo de poder que lo convierte en la figura central del panorama institucional por cuanto retiene el resto del poder no traspasado a las Cortes y a los Tribunales y por ello le corresponde la competencia de las competencias, como lo demuestran la definición general de sus funciones ejecutivas en el artículo 170, la falta de tasación de las mismas en el artículo 171 (que enumera solo las «principales») y la utilización de la expresión «potestad» para atribuir facultades propias e inherentes a los distintos órganos constitucionales en los que residen y no simplemente se delegan ${ }^{56}$.

Cuando el artículo 14 de la Constitución afirma que «el Gobierno de la Nación española es una Monarquía moderada hereditaria» no se está pronunciando

pos, [...]. Hemos acordado voluntariamente y por el libre ejercicio de nuestra autoridad real y acordamos, conceder y otorgar a nuestros súbditos tanto para Nos como para nuestros sucesores y para siempre, de la siguiente Carta Constitucional» (la cursiva es de los autores). Sobre la Monarquía limitada, puede consultarse A. Pérez de Armiñán y de la Serna (1987), en M. FernándeZ-Fontecha Torres y A. Pérez de Armiñán y de la Serna (1987). La Monarquía y la Constitución, Madrd, Civitas, 1987, págs. 20-55.

54 Para Á. MenÉNDEZ ReXACH, la formulación clásica del principio monárquico se contiene en al artículo II, $1^{\circ}$ de la Constitución bávara de 1818 («El Rey es el Jefe del Estado, reúne en sí todos los derechos del poder del Estado y los ejerce conforme a las determinaciones acordadas por él y fijadas en el presente documento constitucional») y fue posteriormente extendido a toda la Federación alemana por el artículo 57 del Acta final de Viena de 1820 en virtud de la cual «dado que la Federación alemana, con excepción de las ciudades libres, está compuesta por reinos soberanos, todo el poder del Estado debe permanecer reunido en el Jefe del Estado, como consecuencia del concepto fundamental aquí establecido, y el soberano sólo puede estar vinculado a la participación de los estamentos en el ejercicio de determinados derechos en virtud de una Constitución estatal». Vid. Á. Menéndez ReXach (1979). La Jefatura del Estado en el Derecho Público Español, Madrid, Instituto Nacional de Administración Pública, pág. 68 y W. Heun (2000). «El principio monárquico y el constitucionalismo alemán del siglo XIX». Fundamentos [en línea], núm. 2. [Consulta: 22 de junio de 2011]. Disponible en web: http://www.unioviedo.es/constitucional/fundamentos/segundo/pdf/ pmonarquico.pdf.

55 D. Sevilla Andrés (1973). «Notas sobre el poder ejecutivo en la Constitución de 1812». Documentación Administrativa, núm. 153, pág. 71.

${ }^{56}$ M. Martínez Sospedra (1978), págs. 311-313. 
sobre una soberanía monárquica que, venteando los nuevos aires, transige sobre su poder y renuncia a parte del mismo para salvar su legitimidad originaria; la cuestión de la soberanía había sido ya previamente resuelta con su atribución a la Nación española en el artículo 3 y no estaba en discusión, máxime cuando en la isla de León la soberanía nacional no era un concepto retórico ni una mera declaración de voluntad e intenciones hacia el futuro sino una realidad operante en el propio momento constituyente en el que la Nación, en ausencia del monarca, se había erigido en sujeto soberano; de ahí que se defina a la Monarquía moderada como «el Gobierno» esto es, como la forma de gobierno de un Estado en el que el monarca ha dejado de ser soberano para convertirse en un poder ejecutivo transmitido hereditariamente. Es claro que el verbo «moderar» del que viene el calificativo tiene un significado muy próximo a limitar y en ese sentido se utiliza la expresión «Monarquía moderada» en el Discurso Preliminar en un contexto referido a las limitaciones a la autoridad regia: «en seguida se proclama igualmente, que el Gobierno de España es una Monarquía hereditaria, moderada por la ley fundamental, sin que en las limitaciones que la modifican pueda hacerse ninguna alteración, sino en los casos y por los medios que señala la misma Constitución» (DP, IX). Sin embargo, no es la Monarquía soberana la que se ha moderado a sí misma otorgando una ley fundamental sino que es la ley fundamental, emanada de una soberanía nacional previa, la que establece una Monarquía moderada al organizarla conforme al principio de división de poderes y determinar las limitaciones que afectan al poder ejecutivo residenciado en el Rey. Es significativo en este sentido que el Discurso Preliminar afirme inmediatamente a continuación la conexión lógica entre la Monarquía moderada, las limitaciones a la autoridad del Rey y la división de poderes ${ }^{57}$. En el mismo sentido, la sistemática del texto constitucional responde a la misma estructura lógica cuando la declaración del artículo 14 va seguida sin solución de continuidad (arts. 15, 16 y 17) de la atribución de las tres potestades clásicas a los distintos órganos constitucionales constituidos en aplicación del principio de división

57 «La Comisión ha mirado como esencialísimo todo lo concerniente a las limitaciones de la autoridad del Rey, arreglando este punto con toda circunspección, así para que pueda ejercerla con la dignidad, grandeza y desembarazo que corresponde al Monarca de la esclarecida Nación española, como para que no vuelvan a introducirse al favor de la oscuridad y ambigüedad de las leyes las funestas alteraciones que tanto han desfigurado y hecho variar la índole de la Monarquía con grave daño de los intereses de la Nación y de los derechos del Rey. Así se han señalado, con escrupulosidad reglas fijas, claras y sencillas que determinan con toda exactitud y precisión la autoridad que tienen las Cortes de hacer leyes de acuerdo con el Rey; la que ejerce el Rey para ejecutarlas y hacerlas respetar, y la que se delega a los jueces y Tribunales para la decisión de todos los pleitos y causas con arreglo a las leyes del Reino» (DP, IX). 
de poderes, todo ello en el Capítulo III del Título I dedicado al «Gobierno» e inmediatamente a continuación de los Capítulos I y II dedicados respectivamente a la Nación española y a la religión. La Monarquía moderada no es sino el trasunto gaditano de aquel Estado moderado del que habla Montesquieu en el que existe la libertad política porque los poderes se frenan entre $\mathrm{si}^{58}$.

Por tanto, por Monarquía moderada se entiende una forma de gobierno basada en la soberanía nacional y en una distribución de las funciones estatales que limita la autoridad — constituída, que no soberana— del Ejecutivo monárquico y sólo en ese sentido lato de Monarquía no absoluta o "pura ${ }^{59}$ ", de gobierno monárquico limitado por una división de poderes establecida en una Constitución emanada de la soberanía nacional parece apropiado calificarla de Monarquía limitada (o constitucional en sentido amplio, para otros sectores doctrinales ${ }^{60}$ ).

\subsection{El Rey como Jefe del Estado}

Una última cuestión suscita la posición del Rey en la Monarquía de 1812, su consideración como Jefe del Estado. El Ejecutivo gaditano es, huelga decirlo, un Ejecutivo monista en el que el Rey es definido por el Discurso Preliminar como «jefe de Gobierno» pero también como «primer magistrado de la Nación» en dos ocasiones y como «Jefe del Estado» en otra. Estas expresiones no son, sin embargo, significativas de que, aún en un sistema monista, se diferencie en Cádiz entre una esfera competencial ligada a la titularidad del poder ejecutivo y otra, propia de la Jefatura del Estado como suprema magistratura estatal, integrada por funciones y competencias de representación de la unidad del Estado subyacente a la división de poderes. Así, el término «primer magistrado de la Nación» se utiliza en un primer caso junto a la expresión «jefe del Gobierno» y en un contexto referido a la titularidad de una enérgica potestad ejecutiva para garantizar el orden, la justicia, la libertad y la seguridad de los ciudadanos ${ }^{61}$; en la segunda

58 «La libertad política no se encuentra más que en los Estados moderados; ahora bien, no siempre aparece en ellos, sino sólo cuando no se abusa del poder. [...] Para que no se pueda abusar del poder es preciso que, por la disposición de las cosas, el poder frene al poder» [MONTESQUIEU (1980). Libro XI, Capítulo IV]. Vid. también A. Torres Del MORAL (en prensa). Epígrafe dedicado al Rey y la monarquía moderada.

59 J. Varela Suances (1987), pág. 185.

60 Ibíd., págs. 185-187.

61 «El Rey, como jefe del Gobierno y primer magistrado de la Nación, necesita estar revestido de una autoridad verdaderamente poderosa, para que al paso que sea querido y venerado dentro de su Reino, sea respetado y temido fuera de él de las naciones amigas y enemigas. Toda la potestad ejecutiva la deposita la Nación por medio de la Constitución en su manos, para que el orden y 
ocasión, se emplea el mismo calificativo a propósito de los poderes ejecutivos atribuidos al monarca en relación con una concepción de la potestad judicial entendida como ejecución de las leyes que exige la publicación de las ejecutorias y provisiones judiciales en nombre del Rey para ampararse en su autoridad ejecutiva a efectos de su respeto y aplicación ${ }^{62}$ y hay que entender, por tanto, la expresión en sentido estricto, esto es como supremo (primer) magistrado o juez de la Nación, aunque carezca de las potestades jurisdiccionales que le han sido celosamente vedadas. Por otra parte, su calificación como «Jefe del Estado» alude a su competencia para ordenar los gastos públicos bajo la supervisión de las Cortes (arts. 171.12, 131.12 y 347), competencia de índole estrictamente ejecutiva y en ningún caso representativa ${ }^{63}$.

Si acudimos, no obstante, a los poderes y facultades regios, se encuentran entre los mismos, junto a los propios de un Jefe de Gobierno, los que la posterior evolución de los Estados monárquicos ha acabado atribuyendo al Rey en cuanto titular de la institución de la Jefatura del Estado con perfiles autónomos del Ejecutivo, si no en la literalidad de los textos constitucionales, sí en la praxis derivada de la introducción progresiva de los mecanismos parlamentarios. Pero no fue posible dar en Cádiz ese paso hacia una Monarquía parlamentaria en la que el Rey abandone en manos de un Gobierno sujeto en exclusiva a la confianza parlamentaria la función de dirección política y el ejercicio efectivo de la potestad ejecutiva (aunque conserve su titularidad formal) y actúe exclusivamente como Jefe del Estado que, pese a estar excluido del poder constituyente, conserve su posición suprema como órgano al que, por expresar simbólicamente la unidad es-

la justicia reinen en todas partes, y para que la libertad y seguridad de los ciudadanos pueda ser protegida a cada instante contra la violencia o las malas artes de los enemigos del bien público» (DP, XXIII).

62 «Aunque la potestad judicial es una parte del ejercicio de la soberanía delegada inmediatamente por la Constitución a los Tribunales, es necesario que el Rey como encargado de la ejecución de las leyes en todos sus efectos, pueda velar sobre su observancia y aplicación. El poder de que está revestido y la absoluta separación e independencia de los jueces, al paso que forman la sublime teoría de la institución judicial, producen el maravilloso efecto de que sean obedecidas y respetadas las decisiones de los Tribunales, y por eso sus ejecutorias y provisiones deben publicarse a nombre del Rey considerándole en este caso como el primer magistrado de la Nación» (DP, XXXVIII).

63 «El Rey, como Jefe del Estado, podrá aplicar según lo crea conveniente al mejor servicio de la Nación los fondos públicos puestos a su disposición por las Cortes. Pero éstas no pueden desentenderse de vigilar sobre la justa inversión, de lo que verdaderamente constituye la sustancia de los pueblos. Para ello es indispensable que el tesorero mayor no haga pago alguno que no sea en virtud de decreto del Rey, refrendado por el secretario del despacho de Hacienda, de cuyo arreglo pende quedar asegurada la responsabilidad de cualquiera malversación» (DP, LXXXIV). 
tatal, corresponde la intervención última en los actos jurídico-públicos más relevantes para manifestar de forma unitaria la voluntad del Estado, sin perjuicio de que el contenido de dicha voluntad venga determinado por los distintos órganos estatales.

Ello hubiera exigido, cuanto menos, tres presupuestos esenciales, además de la soberanía nacional ya concurrente en el texto de 1812: la concepción del Gobierno como órgano separado del monarca con funciones ejecutivas y de dirección política, el establecimiento de una relación de confianza parlamentaria y responsabilidad política del Gobierno con las Cortes y, finalmente, la percepción de un núcleo de funciones representativas propias del Jefe del Estado e independientes de su titularidad formal del poder ejecutivo.

Algunos pasos se dieron en Cádiz hacia la formación del Gobierno como órgano colegiado que ejerciera de facto y bajo una dirección coordinada los poderes ejecutivos del monarca. En el Discurso Preliminar, como ha señalado Tomás Villarroya ${ }^{64}$, se sugería ya esta idea en dos ocasiones: una, al justificar el traslado de responsabilidad a los secretarios refrendantes de los que se sugiere que ejercen de hecho la autoridad del Rey ${ }^{65}$, y otra, cuando la creación del Consejo de Estado se motiva precisamente en la necesidad de coordinar y dar una dirección única y coherente a la acción de los Secretarios ${ }^{66}$.

Se encuentra, sin embargo, ausente del articulado constitucional el concepto de un Gabinete o Gobierno colegiado ${ }^{67}$ integrado por los Secretarios del Despacho y distinto de estos individualmente considerados, así como una Presidencia del mismo que actúe de enlace entre el Gabinete y el Rey; en este sentido, la Constitución sólo incluye al propio Rey, a los Secretarios del Despacho y al Consejo de Estado en el Título IV que, bajo la rúbrica «Del Rey» regula el poder ejecutivo. Por su parte, señala Varela que en el Nuevo Reglamento de la Regencia del Reyno, aprobado por Decreto CCXLVIII, de 8 de abril de 1813, se ar-

64 J. Tomás Villarroya (1981). Breve historia del constitucionalismo español, Madrid, Centro de Estudios Constitucionales, págs. 25-26.

65 «Como el órgano inmediato del Rey lo forman los secretarios del despacho, aquí es en donde es necesario hacer efectiva la responsabilidad del Gobierno para asegurar el buen desempeño de la inmensa autoridad depositada en la sagrada persona del Rey, pues que en el hecho existe toda en las manos de los ministros» (DP, XXIX).

66 «Para dar al Gobierno el carácter de estabilidad, prudencia y sistema que se requiere; para hacer que los negocios se dirijan por principios fijos y conocidos, y para proporcionar que el Estado pueda en adelante ser conducido, por decirlo así, por máximas y no por ideas aisladas de cada uno de los secretarios del despacho, que además de poder ser equivocadas, necesariamente son variables a causa de la amovilidad a que están sujetos los ministros, se ha planteado un Consejo de Estado, compuesto de proporcionado número de individuos» (DP, XXX).

67 I. Fernández Sarasola (2000), pág. 21. 
ticuló una cierta coordinación entre los Secretarios del Despacho al preverse su reunión en Junta, sin que ello supusiera reconocer la existencia de un órgano colegiado ${ }^{68}$. Para Menéndez Rexach, el Consejo de Estado, de nombramiento regio entre los candidatos propuestos por las Cortes -órgano de confianza de las mismas, por tanto, a decir de este autor - vino a asumir las funciones propias de un Consejo de Ministros, aunque limitadas a la deliberación bajo la dirección del monarca, quedando relegados los Secretarios a la mera ejecución de las decisiones del Rey ${ }^{69}$.

Sí surgió, en cambio, a juicio de Sánchez Agesta, una función de gobierno, distinta de la puramente ejecutiva, integrada por la iniciativa legislativa y el veto, la preparación y ejecución del presupuesto, la potestad reglamentaria y la dirección de las relaciones internacionales, tareas todas ellas que «van a suponer un margen de discrecionalidad e iniciativa, propios de una función de gobierno que comienza a apuntar junto a los poderes ejecutivos ${ }^{70} »$; a su juicio, «el poder ejecutivo ya no se limitaba a ejecutar. De una manera imprecisa comienza a asignársele una función más amplia que la historia definirá progresivamente como la función de gobernar ${ }^{71}$ ». Ahora bien, en esta función de gobierno (o dirección política, implícita en el texto constitucional para Varela ${ }^{72}$ ) participarán decisivamente las Cortes $^{73}$, no faltando entre la doctrina quienes entienden que esta participación de las Cortes en la función de dirección política es de tal intensidad que, por ser primordial, autoriza a hablar de un sistema de gobierno asambleario $^{74}$ o convencional o, al menos, próximo al mismo aunque con una posición del ejecutivo y judicial mucho más sólida de lo común en este sistema de gobierno ${ }^{75}$. Para Sánchez Agesta, en cambio, las Cortes no supieron ponderar con realismo el

68 J. VAREla SuAnCes (1987), pág. 55.

69 Á. Menéndez Rexach (1979), pág. 239.

70 L. SÁnChez Agesta (1981). «Poder Ejecutivo y división de poderes». Revista Española de Derecho Constitucional, núm. 3, pág. 23. También I. Fernández SARAsola (2000). Pág. 19-20.

71 Ibíd., pág. 17.

72 J. Varela SuAnCes (1987), pág. 179.

73 En este sentido no hay que olvidar que, junto a la exigencia de su consentimiento para la realización de determinados actos, se atribuían a las Cortes potestades tales como el establecimiento de las aduanas y aranceles de derechos, disponer lo conveniente para la administración, conservación y enajenación de los bienes nacionales, determinar el valor, peso, ley, tipo y denominación de las monedas, adoptar el sistema que se juzgue más cómodo y justo de pesos y medidas, la promoción y el fomento de toda especie e industria y la remoción de los obstáculos que la entorpezcan o establecer el plan general de enseñanza pública en toda la Monarquía (art. 131. 17-22).

74 M. Friera Álvarez e I. Fernández Sarasola. «Contexto histórico de la Constitución española de 1812» [en línea]. Cit.

75 J. Varela Suances (1987), pág. 192. 
formidable peso político que tendría un órgano ejecutivo permanente y de composición reducida con facultades decisivas de iniciativa legislativa y presupuestaria así como de dirección política exterior ${ }^{76}$ (aunque debe decirse que la Comisión redactora sí mostró su preocupación en el Discurso Preliminar ${ }^{77}$ ).

La inexistencia de una relación de confianza política entre el Ejecutivo regio y el Legislativo es notoria en el propio texto constitucional y ha sido generalmente aceptada por la doctrina que coincide en afirmar que mal podían recibirse las prácticas parlamentarias en España cuando o se desconocían o se conocían mal por cuanto la teoría de la separación de poderes se recibió a través de las interpretaciones doctrinales basadas en el texto escrito de la Constitución inglesa sin tener en cuenta las prácticas y convenciones que desarrollaron la colaboración de poderes ${ }^{78}$. El refrendo de los actos del rey por los Secretarios del Despacho supuso un indudable avance pero su responsabilidad era exclusivamente jurídica y en ningún caso política, aunque se señala también por la doctrina que el Nuevo Reglamento de la Regencia del Reyno, aprobado por Decreto CCXLVIII, de 8 de abril de 1813 hizo posible una cierta responsabilidad política de los Secretarios cuya conducta podía ser desaprobada por las Cortes y posteriormente objeto de una acusación penal si hubiera motivo para ello $^{79}$; no obstante, en el Reglamento para el Gobierno Interior de las Cortes, aprobado por Decreto CCXCIII, de 4 de septiembre de 1813, desapareció esa incipiente responsabilidad política manteniéndose sólo la jurídica en los mismos términos que la Constitución ${ }^{80}$.

Por último, si la idea de un Gobierno colegiado y solidario apenas se vislumbró y el régimen parlamentario decididamente no se introdujo en la obra gaditana, faltó también la idea misma de una Jefatura del Estado dotada de funciones simbólicas y representativas. El recelo y desconfianza hacia el Rey que rezuma el Discurso Preliminar y que se trasladó al articulado impidió considerar al monarca en una dimensión institucional superior a la de titular del po-

76 L. SÁNChez Agesta (1981), pág. 23.

77 «El inmenso poder que se ha adjudicado a la autoridad Real necesita de un freno que constantemente le contenga dentro de sus límites; de cualquiera que éstos sean, reducidos a la ineficacia de una ley escrita, sólo opondrán siempre una débil barrera, al que tiene a su mando el ejército, el manejo de la Tesorería y la provisión de empleos y gracias, sin que la autoridad de las Cortes tengan a su disposición medios tan terribles para traspasar los límites prescritos a sus facultades debilitados ya en gran manera por la sanción del Rey» (DP, XVII).

78 L. SÁnchez Agesta (1981), págs. 12-13; y J. Varela SuAnces (1987), págs. 149-150. Para I. FernándeZ SARASOlA, sin embargo, las prácticas parlamentarias de la monarquía británica no eran desconocidas en España atribuyendo a los autores españoles de la época una «ceguera teórica» respecto del sistema de gobierno inglés realmente vigente [(2000), págs. 3-4 y notas 16-17].

79 J. Varela SuAnces (1987), págs. 241-242.

80 J. Varela Suances (1987), pág. 156. 
der ejecutivo. El temor a que el Rey intentara rearmarse con su antigua legitimidad, frente a la concepción revolucionaria de la soberanía nacional, hizo imposible concebir, junto a la representación política de la Nación residenciada en las Cortes, una representación de distinta naturaleza en virtud de la cual la intervención del Rey manifestara simbólicamente la unidad de la soberanía estatal, sin competir por ello con la representación popular ${ }^{81}$. Estaban todos los elementos necesarios, la soberanía unitaria concebida como anterior y previa a los poderes constituidos y la institución monárquica histórica y existencialmente vinculada al Estado; pero la conquista de la soberanía por la $\mathrm{Na}$ ción era demasiado reciente para que las Cortes aceptaran coexistir con una institución que acumulase al poder ejecutivo la representación simbólica de la unidad estatal; si el Rey representaba simbólicamente la unidad del Estado, ello implicaba atribuirle también la representación simbólica de la soberanía unitaria y, aunque no participara en su titularidad y sólo en su ejercicio como poder ejecutivo, suponía compartir con las Cortes la representación de la Nación. Así pues, en Cádiz, aunque buena parte de las funciones posteriormente consideradas propias de un Jefe de Estado parlamentario se encontraban atribuidas al Rey en el articulado constitucional, fueron propiamente las Cortes y no el monarca quienes asumieron la representación simbólica del Estado y de la «autoridad soberana» de la Nación.

Title:

THE FORM OF GOVERNMENT IN THE CONSTITUTION OF CADIZ (REFLECTIONS ON THE CONFIGURATION OF THE HEADQUARTERS OF THE MONARCHIC STATE).

\section{Summary:}

1. Preliminary considerations. 1.1. The first Spanish constitutionalism. Political and legal significance. 1.2. The enlightened monarchy in Spain. 1.3. The legacy of the Enlightenment in the work of the courts of Cadiz. 2. The monarchy in the constitutional state is established in Cadiz. 2.1. National sovereignty. 2.2. The division of powers. 2.3. «Moderate monarchy» and limited monarchy. 2.4. The King as Head of State.

${ }^{81}$ Sobre la función de representación simbólica del Jefe del Estado, vid. G. ROLLNERT LIERN (2002). La Jefatura del Estado: símbolo e integración política en la Constitución vigente, Valencia, Colección Ideas y Políticas Constitucionales, págs. 223-271. 


\section{Resumen:}

A partir de las circunstancias históricas de las Cortes de Cádiz y de los precedentes de la monarquía española, el artículo analiza la posición de la Jefatura del Estado monárquica en la Constitución de 1812 caracterizada como una «Monarquía moderada» basada en los principios estructurales de soberanía nacional y división de poderes que determinan la configuración del Rey como poder constituido en la nueva forma de gobierno.

La afirmación de la soberanía nacional impregna el conjunto del texto constitucional sin perjuicio de que coexista retóricamente con la antigua legitimidad monárquica. Por otra parte, la división de poderes supone la distinción entre la titularidad de la soberanía y su ejercicio por los poderes constituidos, considerándose al monarca el «depositario» del poder ejecutivo frente a unas Cortes que representan a la Nación titular de la soberanía y que, como tales, participan decisivamente en el ejercicio de sus funciones. El alcance de las amplias facultades atribuidas al Rey queda delimitado con las numerosas restricciones que se le imponen en un sistema de rígida separación de poderes.

La «Monarquía moderada» que en Cádiz se proclama no es una simple variante de las monarquías limitadas europeas basadas en el principio monárquico sino una forma de gobierno articulada sobre la soberanía nacional y una distribución de las funciones estatales que limita la autoridad — constituida, que no soberana— del Ejecutivo monárquico. Aunque la Constitución de Cádiz atribuyó al Rey no sólo los poderes propios de un Jefe de Gobierno sino también los que la posterior evolución de los Estados monárquicos ha acabado atribuyendo al Rey como Jefe del Estado con un perfil autónomo del poder ejecutivo, no fue posible dar en Cádiz ese paso hacia una Monarquía parlamentaria en la que el Rey abandone en manos de un Gobierno sujeto en exclusiva a la confianza parlamentaria la función de dirección política y el ejercicio efectivo de la potestad ejecutiva (aunque conserve su titularidad formal), llegándose a tal conclusión sobre la base la ausencia de tres presupuestos esenciales: un Gobierno colegiado separado del monarca con funciones ejecutivas y de dirección política, una relación de confianza parlamentaria entre el Ejecutivo y el Parlamento y, finalmente, un núcleo de funciones representativas propias del Jefe del Estado e independientes de su titularidad nominal del poder ejecutivo.

\footnotetext{
Abstract:

Starting from the historical circumstances of the Spanish Parliament («Cortes») of Cádiz and the precedents of the Spanish monarchy, the article analyses the position of the monarchic Head of State in the Con-
} 
stitution of 1812 characterized as a «moderate monarchy» based on the structural principles of national sovereignty and separation of powers that determine the configuration of the King as a constitutionally limited institution in the new form of government.

The assertion of national sovereignty pervades the whole of the Constitution without detriment to coexist with the old rhetorical monarchical legitimacy. Moreover, the separation of powers involves the distinction between ownership of sovereignty and its exercise by the constitutionally limited institutions, considering the King the «receiver» of the executive branch against a Parliament that, as it represents the Nation owner of the sovereignty, takes a decisive role in the exercise of the King's functions. The scope of the broad powers granted to the King is delimited with the numerous restrictions imposed on a system of strict separation of powers.

The «moderate monarchy» proclaimed in Cádiz is not a simple variant of the limited European monarchies based on the monarchic principle but a system of government founded on national sovereignty and the distribution of state functions that limits the authority - constitutionally limited rather than sovereign - of the monarchic Executive. Although the Constitution of Cadiz confered the King not only the powers of a Head of Government itself but also those that the subsequent evolution of monarchies with time attributes to the King as Head of State power profile independent of the Executive, it was not possible in Cádiz to come in a parliamentary monarchy in which King leaves in the hands of a government exclusively subject to parliamentary confidence the ruling of politics and the exercise of the executive power (although it retains its formal title), reaching such this conclusion on the ground of the absence of three key assumptions: a collegiate government with executive and political power independent of the monarch, a relationship of trust between the Executive and the Parliament and a core of representative functions of the Head of State himself independent of his official title of executive power.

\section{Palabras Clave}

Jefatura del Estado - Constitucion de 1812 - Monarquía parlamentaria - Soberanía nacional - División de poderes.

\section{Key Words}

Head of State - Constitution of 1812 - Constitutional monarchy National sovereignty - Separation of powers. 